\title{
Zeitgeist. Modelando um projeto editorial com interface digital
}

\author{
[Zeitgeist. Modelling an editorial project with digital interface] \\ http://dx.doi.org/10.11606/1982-88372442217
}

\section{Paulo Oliveira ${ }^{1}$ \\ Leandro Ledel ${ }^{2}$}

\begin{abstract}
96. Man könnte sich vorstellen, daß gewisse Sätze von der Form der Erfahrungssätze erstarrt wären und als Leitung für die nicht erstarrten, flüssigen Erfahrungssätze funktionierten; und daß sich dies Verhältnis mit der Zeit änderte, indem flüssige Sätze erstarrten und feste flüssig würden.

97. Die Mythologie kann wieder in Fluß geraten, das Flußbett der Gedanken sich verschieben. Aber ich unterscheide zwischen der Bewegung des Wassers im Flußbett und der Verschiebung dieses; obwohl es eine scharfe Trennung der beiden nicht gibt. [...]

99. Ja, das Ufer jenes Flusses besteht zum Teil aus hartem Gestein, das keiner oder einer unmerkbaren Änderung unterliegt, und teils aus Sand, der bald hier, bald dort weg- und angeschwemmt wird.
\end{abstract}

(WITTGENSTEIN 2004: 15 [Über Gewissheit])

\begin{abstract}
This paper presents the main lines that guide a model for an editorial project for the teaching of German as a foreign language in Brazilian higher education contexts. The discussion contemplates the editorial point of view, technical issues related to the use of digital technology and a teaching-learning concept that provides a theoretical justification for the model presented.
\end{abstract}

Keywords: German as foreign language; teaching material; virtual interfaces; blended learning

Resumo: Apresentam-se aqui as linhas-mestres de um modelo para projeto editorial de materiais didáticos destinados ao ensino de alemão em contextos universitários no Brasil. Contemplam-se o ponto de vista editorial, questões técnicas ligadas ao uso de tecnologia digital e uma concepção de ensino-aprendizagem que dê conta de uma justificação teórica do modelo apresentado.

Palavras-chave: Alemão LE; material didático; interfaces virtuais; formas híbridas de aprendizagem

Zusammenfassung: Die vorliegende Diskussion stellt die Leitgedanken eines Modells zur Publikation eines DaF-Lehrwerks zur Anwendung in brasilianischen Hochschulkontexten vor.

\footnotetext{
${ }^{1}$ Universidade Estadual de Campinas (Unicamp), Reitoria/CEL, R. Cora Coralina, 300 Cid. Univ. Zeferino Vaz, CP-6004, Campinas, SP, Brasil, 13083-896. E-mail: olivp@unicamp.br. ORCID: 0000-0001-60549888

${ }^{2}$ Instituto Federal de Educação, Ciência e Tecnologia de São Paulo (IFSP), Área de Informática, Avenida Thereza Ana Cecon Breda (Vila São Pedro), Hortolândia, SP, Brasil, 13183250. E-mail: leandro.ledel@gmail.com. ORCID: 0000-0003-4607-6548
}

\section{(cc) BY-NC}


Berücksichtigt werden der Standpunkt des Verlags, technische Fragen bezüglich der eTechnologie und ein Lehr-Lern-Konzept, das dem vorgestellten Modell als theoretische Fundierung dienen kann.

Schlagwörter: DaF; Lehrwerkentwicklung; e-Materialien; blended learning

\section{Ponto de partida}

No início das discussões sobre um projeto editorial para o ensino de alemão como língua estrangeira ( $\mathrm{DaF}$ ) em contextos acadêmicos no Brasil, a partir de demanda apresentada por uma editora universitária ${ }^{4}$ nos primeiros meses de 2019, colocou-se a questão se "ainda faz sentido produzir um livro didático no contexto contemporâneo", visto que os/as aluno(a)s cada vez mais se mostram imerso(a)s em contextos digitais e muitas vezes nem trazem o livro didático para a aula, ${ }^{5}$ usando em seu lugar versões - não autorizadas - em pdf. Substituir o xerox pelo pdf é um dos sintomas de fenômeno mais amplo de cópias eletrônicas tomando o lugar do livro impresso. No caso das mídias audiovisuais, a questão torna-se ainda mais complicada, visto que tocadores de CD ou DVD já são raridade, sendo necessário repassar os arquivos para outros suportes, como pendrive ou armazenamento na nuvem, ou convertê-los para formatos eletrônicos como $m p 3$ para som ou mp4 para vídeo. Tal imersão digital não deixa também de ser problemática. A infraestrutura de informática de muitas instituições é precária, e tampouco se pode partir do princípio de que todas as alunas tenham acesso aos recursos de soft e hardware necessários, ou que as conexões de internet sejam confiáveis. No mais, a cultura digital de larga escala leva a comportamentos e expectativas associadas à valorização da imediatez, pela onipresença de programas e plataformas como Facebook, Twitter e WhatsApp, cuja facilidade de uso não só mascara o enorme aparato tecnológico necessário para mantê-las em funcionamento, como também dificulta a percepção de que questões

\footnotetext{
${ }^{3}$ Agradecemos a Norma Wucherpfennig, que (por razões circunstanciais) não pôde participar da redação do texto, por sua leitura atenta, comentários e sugestões; a Mariana Kuntz de Andrade e Silva, por disponibilizar sua dissertação em formato eletrônico, num momento de difícil acesso a repositórios públicos; a Dörthe Uphoff, pela leitura atenta e crítica, e por disponibilizar sua tese e outros títulos importantes para o debate; a toda a equipe de Zeitgeist, pela discussão que levou-nos à presente reflexão. Quaisquer deficiências são de nossa exclusiva responsabilidade.

${ }^{4}$ Essa demanda não significa garantia de publicação, que depende de aprovação do Conselho Editorial, após análise do produto concreto. Tampouco significa que a proposta não possa vir a se concretizar por outras vias.

${ }^{5}$ Por razões de economia e legibilidade, passaremos a fazer as referências genéricas (ou no plural) apenas no feminino, apontando assim para o fato de que marcas de gênero expressam relações de poder e de que essas devem ser questionadas, no sentido da busca por tratamento igualitário. Se o masculino é passível de ser lido como termo genérico, o feminino também o é (aqui, com referências abstratas, manteve-se o masculino). Em citações, mantivemos o tratamento dado no original - com ou sem diferenciações.
}

Pandaemonium, São Paulo, v. 24, n. 42, jan.-abr. 2021, p. 217-254 
complexas demandam aprofundamento, o que por sua vez demanda tempo de reflexão, etc. $^{6}$

O presente ensaio explora o horizonte de possibilidades e limitações para um projeto editorial que queira dar conta da inexorável passagem para o virtual, numa sociedade globalizada e cada vez mais pervadida pela tecnologia digital e seus mecanismos de inteligência artificial, reconhecendo ao mesmo tempo as enormes disparidades que condicionam os potenciais contextos de aplicação dos materiais didáticos (MDs) a serem disponibilizados a seu público-alvo. Trata-se aqui de estudo exploratório oriundo de um contexto acadêmico com forte propensão à pesquisa de ponta, nas mais variadas áreas do conhecimento, no qual se procuram soluções que atendam de modo adequado a contextos específicos, como resposta local a questões formuladas de modo global - segundo o mote think globally, act locally (OLIVEIRA 2002). Devido ao caráter eminentemente transversal da discussão, abarcando desde questões teóricas de fundo até aspectos eminentemente práticos/técnicos em diferentes áreas, em alguns pontos não faremos mais do que arranhar a superfície do debate, desvelando sua complexidade, porém sem aprofundar-nos em todos os aspectos evocados - até mesmo para não perder de vista o foco da discussão. Se a interligação dos tópicos e sua relevância para o modelo proposto tiverem ficado evidentes ao final do texto, ele já terá cumprido sua função.

Para uma melhor compreensão da proposta, revisitaremos brevemente algumas etapas do caminho que levou a ela, no tocante à abordagem didática e à convergência com questões de tecnologia ou do espaço virtual (Subseção1.2). Note-se que o lugar onde se consolidou tal experiência é marcado pela função de dar soluções a demandas institucionais concretas, fazendo uma ponte entre a pesquisa acadêmica e aplicações práticas - a exemplo do que fazem hoje start ups em outras áreas, voltadas para demandas "da sociedade" ou "do mercado". Antes desse relato, cabe explicitar, no plano teórico, a importância do cenário onde se dá o ensino-aprendizagem de línguas e o papel que os diferentes MDs podem nele exercer, para termos uma apreensão mais adequada da proposta editorial em tela (1.1). Na sequência, faremos uma discussão mais técnica dos fatores envolvidos na implementação e utilização de uma interface digital (Seção 2), para

\footnotetext{
${ }^{6}$ Muitos aspectos desse cenário inicial tornaram-se mais agudos com o advento da pandemia de Covid-19 e a expansão exponencial do uso de recursos virtuais para ensino remoto (emergencial). A discussão dessas inflexões, no entanto, ficará, necessariamente, para um momento futuro. Sobre o tema, vide edição especial de Pensar a Educação, ano 6, vol.6 n.1: https://pensaraeducacaoemrevista.com.br (26/6/2020).
} 
que se tenha uma ideia, ainda que aproximada, do rol de decisões a serem tomadas, com suas implicações para a produção, comercialização e utilização dos MDs. É certo que questões dessa natureza não costumam ser alvo da reflexão acadêmica quando se discute o uso de recursos digitais no ensino de línguas - mote do presente volume - e que a linguagem usada não poderá ser excessivamente técnica. Esperamos ter encontrado o equilíbrio adequado entre legibilidade - para o público da revista - e o necessário rigor conceitual. Por fim, na Seção 3, retomaremos, de um ponto de vista mais abstrato, alguns dos tópicos tratados sob outras óticas nas seções anteriores, visando situar o estatuto teórico tanto da proposta editorial em si (1.3) quanto da experiência institucional sintetizada em 1.2.

1.1 Ensino de língua estrangeira (LE) vs. segunda língua (L2), material didático slobal vs. regional/localizado ou local

Do ponto de vista estritamente comercial, a demanda da editora visa suprir uma lacuna que surgirá no momento em que o um de seus títulos (Blaue Blume) deixar de estar na base das disciplinas de alemão na Unicamp, Instituição de Ensino Superior (IES) à qual está vinculada, após cerca de década e meia de uso. À parte esse aspecto mais pragmático, tem-se também o reconhecimento da importância do ensino, ao lado da dimensão estritamente acadêmica que orienta a composição do catálogo da Editora da Unicamp em termos gerais. Quando de sua inclusão no catálogo, Blaue Blume representou uma novidade nesse sentido (OLIVEIRA 2006), e a experiência acumulada desde então aponta para um potencial ainda não plenamente explorado, do ponto de vista editorial, das aplicações didáticas no meio acadêmico, i.e., de materiais que possam integrar-se às bibliografias dos cursos e/ou disciplinas.

Materiais didáticos para o ensino de línguas deixam-se organizar em diferentes categorias, segundo seu modo de produção e o público a que se destinam.

Primeiramente, nos estudos sobre MDs é fundamental considerar que existem diferentes tipos de materiais e que cada um deles é pensado para uma determinada finalidade. Desse modo, concordamos com López-Barrios e Villanueva de Debat (2014) sobre a importância de definir e caracterizar esses materiais em globais, localizados e locais ${ }^{[104]}$. Para Tomlinson (1998, p.x), um material global é aquele que "não é escrito para aprendizes de uma determinada cultura ou país, mas cuja intenção de uso é direcionada para qualquer aprendiz, de um determinado nível e idade de qualquer lugar do mundo"[105]. Hadley (2014) complementa que o material global se tornou, no século 21, um dos maiores recursos pedagógicos para o ensino de uma LE, especialmente por seu forte apelo comercial e editorial. Os outros tipos de MDs referem-se, 
respectivamente, aos materiais localizados (ou glocais ${ }^{[106]}$ ), $[\ldots]$ a versão adaptada de um material global [,] e aos materiais locais ${ }^{[1107]}$. Espera-se que o material localizado consiga relacionar as necessidades e os interesses dos aprendizes de modo mais contextualizado [...]. Em nossa compreensão, os materiais localizados apresentam-se como uma alternativa favorável para o processo de ensino-aprendizagem de uma LE no contexto público de ensino. Especialmente porque os professores podem lançar mão do recurso da adaptação para transformar a proposta original de um MD, (re)significando assim a importância desse instrumento didático, de modo que esse material consiga representar a realidade de seus aprendizes. (LUCAS 2016: 87-88; destaques acrescidos) $)^{7}$

$\mathrm{Na}$ área de $\mathrm{DaF}$, usa-se comumente outra terminologia, diferenciando produções internacionais de edições regionais (internationale vs. regionale Lehrwerke), com menos ênfase em produções locais - quase uma raridade no país (cf. UPHOFF 2009: 80-88). Para nossos propósitos, a divisão tripartite é mais funcional, pois permite caracterizar adequadamente o que está em jogo e enfatizar a versão local. A versão brasileira de Blaue Blume insere-se claramente na categoria de material localizado/regional, sendo esse MD ( Lehrwerk) a única variante com produção local de um material global que já em sua concepção original previa alguma diferenciação regional - seja pelo simples uso de metalinguagem na língua das aprendizes, conforme as tradições de cada país. A opção por uma versão brasileira levava em conta diferenciações no contexto de ensinoaprendizagem (OLIVEIRA 2006), se de Língua Estrangeira (LE) ou Segunda Língua (L2), ${ }^{8}$ num momento em que se discutiam alternativas concretas para a produção de MDs de DaF no Brasil (Bolognini ET AL. 2008; BoHUNOvSKy 2011).

A despeito dessa discussão, o caso mais comum nas últimas décadas continua a ser a utilização de MDs globais, produzidos em países nos quais o alemão é (um) idioma oficial. Como aludido na citação de Patrícia Lucas (2016) acima, tais materiais não são pensados em termos do ensino de LE, com a possibilidade de mobilizar uma metalinguagem comum às aprendizes (de modo geral, sua língua materna), e levando em conta as aplicações mais imediatas que o conhecimento da LE possa vir a ter. Nesse último caso, o potencial de uso efetivo, em contextos de não-imersão, é diverso daquele ligado à pragmática de situações do cotidiano ou, mais recentemente, a aspectos específicos da realidade de migrantes, pessoas em situação de refúgio etc. - tendo em comum a imersão na língua alvo (L2), pressuposto mormente privilegiado na produção

\footnotetext{
${ }^{7}$ Interpolações nossas, cortes em citações e eventuais notas (omitidas na citação) vêm entre colchetes [...]. Nossa discussão gira em torno dos tópicos destacados.

8 Mais recentemente, agregou-se à discussão o conceito de Língua Adicional, no debate sobre o plurilinguismo.
} 
editorial voltada para uso global, numa leitura estrita do Quadro Europeu Comum de Referência para as Línguas $(\mathbf{Q E C R}=\mathbf{Q U A D R O})$. Por outro lado, aprendizes inseridas inicialmente numa situação de LE também têm em seu horizonte a possibilidade de imersão futura em contextos de L2, o que em parte explica o sucesso de MDs globais e justifica sua utilização em contextos de LE - nos quais MDs localizados/regionais ou mesmo locais deveriam ter a prioridade. O modelo para Zeitgeist aqui proposto leva em conta essa possível complementariedade, conforme discutido brevemente na Seção 3 (ver também função do círculo externo do modelo, na Subseção 1.3)

\subsection{Percurso institucional na Unicamp}

Segundo Dietmar Rösler e Nicola Würffel, mudanças técnico-mediáticas no ensino de DaF trazem em seu bojo o risco tanto de "rejeição irracional" quanto de "expectativas iniciais demasiadamente elevadas", com repercussões negativas em ambos os casos. Um outro problema seria certa tendência a "tratar o uso da mídia como caso especial, inovação etc.”, passando ao largo do reconhecimento de que "cada uso específico deve ser inserido numa longa linha de discussão didática" (RÖSLER \& WÜRFFEL 2017: 252-253). ${ }^{9}$

$\mathrm{Na}$ síntese a seguir, procuramos dar conta da inserção dos diferentes usos de tecnologia na discussão e prática didática na Unicamp, visando ilustrar como a integração de novos recursos às mídias tradicionais ocorreu de forma paulatina e interligada com questões conceituais, de método, testando-se sempre os limites da aplicabilidade aos contextos dados. Trata-se de um percurso relativamente extenso, com fases de testes e/ou aplicação que permitissem também algum acompanhamento de caráter longitudinal.

Desde seus primórdios, o trabalho com DaF na Unicamp seguiu basicamente as tendências internacionais, aderindo aos respectivos paradigmas em voga (cf. UPHOFF 2009: 63-80), a começar por manuais cognitivistas tradicionais até o início da década de 1970, passando depois para o áudio-lingual e aderindo relativamente cedo à abordagem comunicativa - e a MDs globais mainstream - no final da década de 1980. Em meados dos anos 1990, duas novas tendências tomam forma, a começar pela exploração de outras possibilidades de ensino-aprendizagem, contemplando também variações da modalidade a distância, inclusive com a produção de MDs in loco - parcialmente em cooperação

\footnotetext{
${ }^{9}$ Todas as traduções direto do original são nossas.
} 
com a FernUniversität Hagen (SARTINGen; Oliveira; Degelo 1997). ${ }^{10}$ O passo seguinte foi aderir a MDs globais fora do mainstream, destinados a um público adulto com interesses culturais, a exemplo de Die Suche (Langenscheidt), que se apresentava como "o outro MD” (,, das andere Lehrwerk") para DaF. Dentre os diferenciais que tornaram Die Suche interessante naquele contexto, destaquem-se a valorização da dimensão expressiva da linguagem, com recurso sistemático à literatura, e a mobilização de textos mais complexos do que os usualmente encontrados em MDs mainstream.

Essa tendência foi acompanhada por um trabalho sistemático de compatibilização de recursos online com a utilização de MDs em suportes tradicionais, na modalidade de blended learning (combinação de estudo presencial e a distância, suportes empíricos e virtuais), com produção in loco de comentários, disponibilização de material complementar, etc. A experiência de vários anos com Die Suche mostrou ser acertada a opção por trabalhar com textos mais complexos, não restritos à pragmática do cotidiano e sem priorizar claramente a produção oral, como no mainstream da época. Tal foco num nicho mais específico foi um fator crucial $^{11}$ quando da opção por adotar um MD localizado/regional, propondo sua produção à Editora da Unicamp - após fase piloto com a versão em espanhol de Blaue Blume, produzida na Alemanha, uma vez mais com suporte adicional elaborado in loco e disponibilizado via ferramentas virtuais.

Contribuiu para tal proposta de uma abordagem híbrida o fato de que havia, na própria Unicamp, uma forte linha de pesquisa em informática voltada para fins educacionais, da qual resultou, dentre outros, o TelEduc (NIED 1997-2017), Ambiente Virtual de Aprendizagem (AVA) pioneiro - nacional e internacionalmente. Tanto os MDs em uso à época quanto o TelEduc remetiam a referenciais teóricos construtivistas ou socioconstrutivistas, o que facilitou sua convergência e uso combinado - não cabendo aqui discutir forma nem grau dessas relações (por razões de foco e espaço). Na sequência,

\footnotetext{
${ }^{10}$ Tal produção in loco tivera início em período anterior, de intensa experimentação sem recurso ao livro didático, notadamente - mas não só - em disciplinas voltadas para a leitura de textos originais. Viviam-se os anos iniciais da Linguística Aplicada no Brasil, quando o foco principal ainda estava no ensino de línguas. No plano teórico, discutiam-se intensamente questões como a distinção adquirir vs. aprender (na esteira de Krashen), abordagens top-down vs. bottom-up etc. Da falta de um fio condutor - papel usualmente delegado ao livro didático - emanaram vários problemas, como: 1) trabalho limitado à sala de aula, com prejuízo da aprendizagem autônoma; 2) falta de recursividade, com prejuízo da aquisição sistemática, sobretudo lexical; 3 ) descompasso entre disciplinas ministradas por diferentes docentes, com prejuízo da coerência institucional nos níveis oferecidos.

${ }^{11}$ Cf. Michael Schart sobre o uso de Die Suche no Japão, notadamente no tocante às conclusões sobre a herança positiva desses MDs - não obstante sua não consolidação como alternativa comercialmente viável, mesmo que dirigida a um nicho específico (SCHART 2005: 16-17). Parte significativa dessa análise aplicase ainda hoje, como possível horizonte - mutatis mutandis - para Zeitgeist.
} 
surgiram novos AVAs, alguns de uso comercial e tecnologia proprietária, como o Blackboard (da Microsoft), ${ }^{12}$ outros baseados em código aberto, como o Moodle. ${ }^{13}$ Vários fatores levaram a uma migração gradual para o Moodle, como: seu referencial socioconstrutivista; a filosofia de software livre, colaborativo e de código aberto, sem custos de licença; e também, como grande diferencial, uma forte convergência com as tendências de software não educacionais de utilização em larga escala, além da possibilidade de integração com alguns deles.

Ainda que o que estivesse em jogo fossem propostas de aplicação eminentemente prática, as experiências acumuladas ao longo desse percurso não deixaram de ser compartilhadas com a comunidade de pesquisa, seja em encontros acadêmicos ou publicações especializadas. Tais contribuições remontam aos primórdios da utilização de computadores para fins didáticos (OLIVEIRA 2000, 2001) e ao surgimento dos AVAs (OliveIRA 2003), relatam várias explorações do potencial - e das limitações - de ferramentas virtuais específicas para determinadas finalidades didáticas (OLIVEIRA 2007, 2008, 2009, 2012, 2015), discutem conceitos como formas híbridas (OLIVEIRA; WuChERPFENNiG; VetTer 2008), ${ }^{14}$ passagem para o virtual (OliVeIRA; WUCHERPFENNIG 2011), diferenciação para grupos específicos (HERZIG ET AL. 2015) e, last but not least, abordam também aspectos eminentemente técnicos, referentes ao próprio desenvolvimento e gerenciamento de ferramentas eletrônicas (LEDEL; RICARTE 2004; LEDEL 2010).

Entre um passo e outro nesse itinerário, a Editora da Unicamp publicou, em 2006, o MD localizado/regional Blaue Blume, que tem como grande diferencial o recurso sistemático e quase exclusivo a textos autênticos, de diversos gêneros, e em grande parte com um nível de complexidade bem maior do que o usualmente encontrado em MDs globais mainstream, possibilitando assim também uma diferenciação clara entre as atividades voltadas prioritariamente para a recepção ou a produção na LE. Dentre as restrições feitas a Blaue Blume quando de sua primeira edição no Brasil, estão dúvidas quanto à utilização do português (formuladas certamente a partir da aderência a um monolinguismo estrito) e a opção por abordar temas "pesados" e questões complexas, ou mesmo polêmicas, afastando-se da pretensa "objetividade /neutralidade" dos MDs de

\footnotetext{
${ }^{12} \mathrm{https} / / /$ blackboard.grupoa.com.br/sobre-a-blackboard/

${ }^{13} \mathrm{https} / / /$ moodle.org/?lang=pt br

${ }_{14}$ Estudo comparativo envolvendo uma plataforma aberta (TelEduc, Unicamp) e outra dedicada: projeto $D U O$, da Universidade de Munique, com aplicação piloto em curso de verão no CEL/Unicamp.
} 
Oliveira, P.; Ledel, L. - Zeitgeist. Modelando um projeto editorial

ampla aceitação (cf. OLIVEIRA 2006 para mais detalhes). Sintomaticamente, tais aspectos entram agora no rol das opções a serem radicalizadas na passagem para a construção de um MD local (cf. 1.1), sob a égide de conceitos como o letramento crítico e a intercompreensão, aliados a uma abordagem potencialmente contrastiva alemão/português que não perca de vista o preceito do monolinguismo esclarecido (aufgeklärte Einsprachigkeit).

A despeito da clara relevância de contribuições de cunho mais reflexivo como as elencadas acima, seja lembrado uma vez mais que os diversos objetivos visados ao longo do percurso tinham em seu horizonte sobretudo soluções concretas, aplicáveis a contextos bem delineados - com base em parâmetros teóricos com justificação própria, é certo (cf. Seção 3). É com essa mesma atitude que o projeto atual - e sobretudo o modelo aqui discutido - se orienta $(\mathrm{m})$ também pelo primado da práxis, levantando sempre a questão da exequibilidade das propostas teóricas em pauta e procurando meios para implementá-las - sem deixar, no entanto, que se tornem idealizações abstratas e inalcançáveis. Na sequência, destacamos alguns dos fatores mais relevantes em jogo, a partir de diferentes perspectivas.

\section{$1.3 \bigcirc$ projeto editorial Zeitgeist}

Retomando o fio da demanda inicial colocada agora, registre-se que, do ponto de vista da Editora da Unicamp, dois fatores se configuram desde já como fundamentais. O primeiro deles diz respeito à dificuldade e aos custos da obtenção de direitos autorais, com base na supracitada experiência da produção de Blaue Blume. Daí sua solicitação no sentido de que fossem usados sobretudo textos, escritos ou audiovisuais, que já pertençam ao domínio público - ainda que a legislação brasileira seja bastante generosa no tocante à utilização para fins didáticos (cf. PREVEDELLO ET AL. 2015: 35-37). ${ }^{15}$

Conforme já registrava Chris Mares,

\footnotetext{
${ }^{15}$ No caso de MDs para $\mathrm{DaF}$, cabe levar em conta que materiais autênticos virão sobretudo de países com legislação mais restritiva, o que torna ainda mais sensível a "zona cinzenta" em jogo. Mesmo normas internacionais bastante liberais (cf. https://creativecommons.org/licenses/by-nc-sa/4.0/) exigem, dentre outros, autorização explícita também em uso não comercial - fato esse frequentemente ignorado no contexto brasileiro: "A falta de conhecimento sobre [a] LDA [Lei dos Direitos Autorais], quando se trata de EaD [Ensino a Distância], segundo Blattmann e Rados (2001) e Maia e Mattar (2007), ainda sofre com um equívoco, amplamente difundido, [quando] se propaga a ideia de que, se o uso for educacional, não é necessária a preocupação com o direito autoral. Mas, ao contrário disso, 'o uso educacional de determinada obra intelectual não significa dar respaldo ao uso pirateado' (BLATTMANN; RADOS, 2001, p. 91)” (Prevedello et AL. 2015: 30).
} 
escrever um livro didático é apenas uma parte do processo de levar o material para as salas de aula. O trabalho é, na maioria das vezes, feito sob contrato com uma editora, o que significa que outras forças além de uma sólida pedagogia [...] estão agindo. Estas forças refletem basicamente as restrições do mercado. ([Mares 2003: 132] apud UPHOFF 2009: 94)

Dörthe Uphoff sugere que a experiência com MDs que fogem ao mainstream corrobora esse raciocínio, e cita como exemplos Die Suche - caso já referido acima - e

\section{Dimensionen:}

Assim, o livro didático "Dimensionen" (JENKINS et al., 2003), por exemplo, recebe críticas muito positivas em revistas especializadas, devido à sua abordagem considerada inovadora (cf. OEBEL, 2008). Entre os aspectos mais elogiados figuram uma seleção de conteúdos e de temas que não se baseia meramente em situações comunicativas do cotidiano, e uma progressão relativamente flexível, que concede bastante liberdade ao professor, na hora de planejar o seu ensino. Apesar desses atributos, o livro, até hoje, não se tornou um sucesso de mercado. Na opinião da autora Jenkins (2006, p. 51), que faz um balanço da repercussão do material, a situação se deve justamente à proposta inusitada do livro, que vai claramente na contramão do mainstream dos livros didáticos atuais. (UPHOFF 2009: 95; destaques acrescidos)

Além de considerações de método, o balanço de Jenkins, alinhando-se ao que foi colocado na citação de Mares [2003], contempla também a questão dos direitos autorais, especialmente sensível no contexto das novas mídias e demandas contemporâneas:

O que os defensores de materiais autênticos esquecem ou não sabem: autenticidade custa dinheiro. E muita autenticidade leva os custos de produção às alturas! [...] [S]obretudo em nossa era visual, como muita gente quer colocar suas fotos na Internet ou aparecer na televisão, torna-se cada vez mais difícil obter direitos de imagem e texto, especialmente de textos falados no rádio ou na televisão. Todos membros da equipe querem ou devem ganhar dinheiro com a produção, cabendo respeitar os direitos pessoais para cada imagem! É isso o que explica o quadro atual: os/as autor@s de material didático escrevem -como dantes- os textos de seus próprios livros ou, na melhor das hipóteses, adaptam textos autênticos até que pelo menos um pouco de "autenticidade moderada" permaneça, sem que o/a redator(a) do texto original perceba. De alguma forma, soa autêntico quando o/a autor(a) tem algum talento. (JENKINS 2006: 57) ${ }^{16}$

O segundo fator elencado inicialmente pela editora é de natureza técnica e logística: tendo em vista a obsolescência de suportes tradicionais de mídia como CD e

\footnotetext{
${ }^{16}$ Em trabalho mais recente, Mariana Kuntz de Andrade e Silva (2016) retoma criticamente esse descompasso entre a exigência teórica da autenticidade em MDs para o ensino de $\mathrm{DaF}$ e a produção editorial sustentada por textos "semi-autênticos". As duas abordagens do mesmo tópico refletem perspectivas distintas, correspondentes, respectivamente, ao ponto de vista da autora/editora ou da academia, e representam apenas a ponta do iceberg, não se restringindo - de modo algum - apenas a esse tópico específico ou às autoras referidas. Estão em jogo questões complexas, envolvendo também a relação entre teoria e prática, a importância e os limites da facilitação didática etc. Os riscos, nas duas pontas, manifestam-se sobretudo quando um discurso se sobrepõe dogmaticamente ao outro, sem alcançar a síntese necessária. Superar o fosso que separa o discurso acadêmico crítico e uma prática didática que, nas IESs brasileiras, mobiliza fortemente os MDs globais, é um dos principais desafios colocados ao projeto editorial Zeitgeist. Retomaremos esse assunto na Seção 3.
} 
DVD, todo material audiovisual deverá ser integrado ao livro na forma de $\boldsymbol{Q R C o d e}$ que remeta diretamente a um endereço na internet (cf. discussão técnica na Seção 2). $\mathrm{O}$ mesmo procedimento torna possível agregar outros elementos ao livro didático em si, como variantes lúdicas e/ou ferramentas de acessibilidade. Com isso, o acesso à internet é colocado desde já como uma condição imprescindível para a utilização plena, ou minimamente adequada, dos MDs a serem elaborados. Tal quadro não significa, por outro lado, que o acesso tenha necessariamente de ocorrer em condições ótimas - até mesmo porque isso implicaria passar ao largo do reconhecimento de que os esforços de inclusão digital no Brasil ainda estão longe de alcançar resultados minimamente satisfatórios (PRIOSTE \& RAIÇA 2017). Em contextos onde houver restrições técnicas, seja da instituição ou de parte significativa das alunas, resta às responsáveis pelo curso a alternativa de acessar as mídias necessárias e fazer uma cópia para uso em sala de aula, quando for o caso, ou também disponibilizar esse ou outro material adicional às alunas, para cópia impressa ou uso digital offline (arquivos em $p d f$ ou $m p 3$, por exemplo).

Para além desses parâmetros iniciais estabelecidos pela própria editora, o conhecimento de alternativas com uso mais intenso de tecnologia digital (cf. 1.2), aliado à convicção de que a passagem para o virtual (OLIVEIRA; WUCHERPFENNIG 2011) é uma tendência inexorável, levou o núcleo campineiro da equipe autoral - que agrega também pesquisadoras de várias outras IESs públicas - a elaborar um modelo mais complexo, sintetizado na Figura 1, abaixo. O princípio básico é explorar as características intrínsecas de cada mídia, levando em conta fatores como seus respectivos graus de perenidade e/ou acessibilidade, possibilidades de atualização, exigências de segurança e, last but not least, custos de produção e/ou manutenção. Em grandes linhas, trata-se de equacionar via formas híbridas a demanda colocada por Dietmar Rösler para MDs eletrônicos:

Portanto, o MD [Lehrwerk] eletrônico deve, pelo menos, integrar tudo o que antes era transportado de maneira significativa em um livro do curso impresso e seus complementos, como livro do aluno e manual do professor, glossários, cassetes, transparências etc. Quando se fala de um MD digital, espera-se que as funções dos diferentes componentes dos MDs tradicionais sejam 'suspensas' na outra forma multimedial - de três maneiras: abolidas em relação à forma material, preservadas em relação a diversas funções e aprimoradas em termos de interação entre os componentes, explorando o potencial multimídia. (RÖSLER 2010: 78-79)

No modelo sintetizado na Figura 1 (abaixo), atribui-se ao livro didático em formato impresso o papel de disponibilizar um programa mínimo que sirva ao mesmo 
Oliveira, P.; Ledel, L. - Zeitgeist. Modelando um projeto editorial

tempo como fio condutor e material de base para a apresentação de paradigmas, sejam eles temas relevantes, gêneros textuais, tópicos de gramática ou sistematização lexical, etc. Cabem aqui preferencialmente textos que não venham a envelhecer rapidamente, i.e., que garantam algum grau de perenidade, de modo a evitar a necessidade de atualizações que teriam reflexo também nas seções de sistematização e exigiriam novas edições impressas. Contribuiu para a formulação desse princípio a experiência consolidada com Blaue Blume ao longo de década e meia de uso institucionalizado na Unicamp: os textos mais antigos não envelheceram, os textos mais recentes ou que tratassem de tópicos muito vinculados a contextos específicos perderam sua atualidade, sendo não raro até mesmo difícil compreendê-los e, sobretudo, torná-los interessantes para um público-alvo imerso numa realidade muito distinta. ${ }^{17}$

Figura 1: Mídias e níveis/tipos de acesso

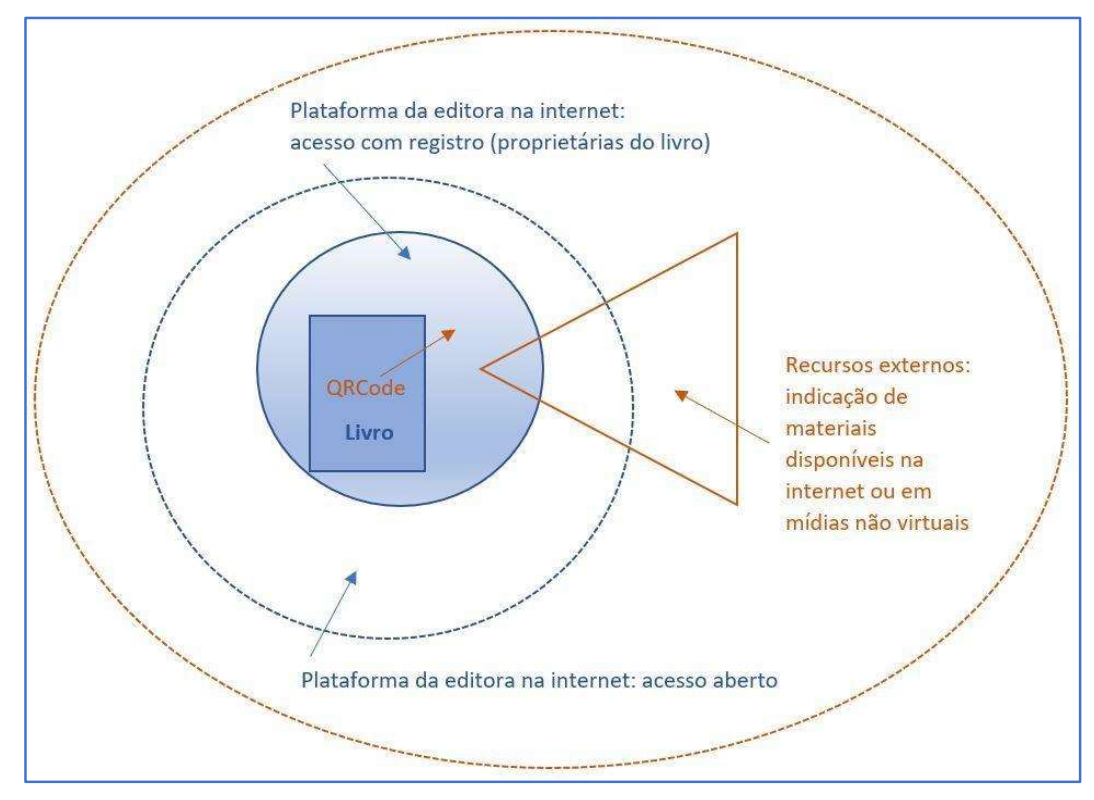

Fonte: elaboração própria

\footnotetext{
${ }^{17}$ Ainda que aspectos técnicos e pragmáticos tenham maior saliência na proposta, cumpre lembrar que a relação entre o que é relativamente estável ou intrinsecamente fugidio é mais complexa e profunda. Se assumirmos, com Humboldt, que a linguagem funciona como um organismo, saberemos que tudo o que nela é, veio a ser. Alguns fenômenos, porém, são mais estáveis; outros, mais voláteis. O domínio da gramática, por exemplo, é mais abstrato e muda muito mais lentamente que o do léxico (KOLLER 1988: 86). Um dos insights mais profundos do Witttgenstein tardio é que, também na linguagem e no pensamento, o movimento pressupõe uma referência estável: "Se quero que a porta gire, é preciso que a dobradiça esteja fixa" (WITTGENSTEIN 2004: 44 [§ 343]). Nossa epígrafe e nosso argumento giram em torno dessa questão: "Ja, das Ufer jenes Flusses besteht zum Teil aus hartem Gestein, das keiner oder einer unmerkbaren Änderung unterliegt, und teils aus Sand, der bald hier, bald dort weg- und angeschwemmt wird" (WITTGENSTEIN 2004: 15 [§ 99]).
} 
Oliveira, P.; Ledel, L. - Zeitgeist. Modelando um projeto editorial

Na Unidade 2 de Blaue Blume, por exemplo, trabalha-se com um poema (Dualismus) e trechos da cartilha visual Orbis sensualium pictus, do pedagogo Johann Comenius (1592-1670), ambos imunes à ação do tempo. Efeito semelhante tem-se no tratamento dado à Unidade 4, que mobiliza o tema Synästhesie. Por outro lado, não surpreende que a "linguagem juvenil" abordada na Unidade 49 tenha rapidamente envelhecido, algo que também ocorre com a Unidade 33, no tocante aos hábitos televisivos na Alemanha Ocidental do pós-guerra. Um caso particular é a postura dos alemães diante da questão do nacionalismo, abordada na Unidade 28 (Die Suche nach den Deutschen). Se na década de 1990 esse ainda era um tema tabu, hoje o recrudescimento dos movimentos de direita nacionalista o coloca novamente em pauta: o texto de João Ubaldo Ribeiro (retirado do livro Ein Brasilianer in Berlin [1994]), que antes tinha interesse para a discussão intercultural, passa a ter caráter eminentemente histórico. Certos temas têm um caráter mais perene, sendo sua ênfase um dos princípios basilares em Zeitgeist. A passagem para o virtual permite dar a eles um tratamento contemporâneo, na plataforma digital. Tome-se como exemplo o racismo, abordado na Unidade 12 de Blaue Blume (Ein Farbiger). A morte de George Floyd, sufocado em 2020 por um policial nos EUA, levou a protestos generalizados no mundo todo, reacendendo a discussão, a ponto de cogitar-se a retirada do termo Rasse da Grundgesetz alemã. Uma tal discussão - atual - condiz com o círculo interno da Figura 1.

As mídias disponíveis via $Q R C o d e$ no livro devem passar por crivos semelhantes, sua disponibilização ocorrendo via plataforma da editora (qualquer que seja ela), não cabendo no livro o uso de links para fontes externas, sujeitas a alterações que fujam ao controle do projeto editorial. ${ }^{18}$ Daí decorre também que todo e qualquer texto que vier a ser disponibilizado no livro ou seja acessível na plataforma da editora via QRCode contido no livro deve contemplar os devidos direitos autorais - aí inclusa a possibilidade de se recorrer a material de domínio público, com utilização autorizada para fins didáticos ou que tenha copy left, i.e., cuja utilização seja autorizada desde que citadas as fontes e respeitados alguns parâmetros adicionais, como no caso da creative commons. ${ }^{19}$

\footnotetext{
${ }^{18}$ No final de 2019, o sítio da Diretoria Acadêmica da Unicamp foi vítima de um ataque cibernético que afetou também o provedor do Moodle institucional, cujo restabelecimento - parcial - só ocorreu com o $1^{\circ}$ semestre letivo de 2020 já em andamento. Com isso, parte do material didático de disciplinas anteriores tornou-se inacessível, sendo necessário resgatar cópias de segurança locais mais antigas. Muitos links externos disponibilizados nessas disciplinas antigas de alemão haviam caducado, com perdas da ordem de até $50 \%$, em alguns casos.

${ }_{19}$ Cf. https://br.creativecommons.org/licencas/. Sobre ensino remoto, vide: https://youtu.be/ohBwRMJ_Oho. (31/07/2020).
} 
Oliveira, P.; Ledel, L. - Zeitgeist. Modelando um projeto editorial

Para além de se configurar como repositório para as mídias referidas através de QRCode no livro, esse espaço interno da plataforma da editora, acessível somente para usuárias registradas, apresenta-se também como possível fonte de material adicional, com uma flexibilidade inexistente na mídia impressa. A restrição de acesso cumpre duas funções distintas, mas complementares. Por um lado, há o aspecto comercial, da venda de um produto e/ou serviço que demanda cobertura de seus custos de produção e eventual manutenção. Por outro lado, colocam-se demandas de segurança face às inúmeras possibilidades de ataques a que estão submetidos quaisquer dados disponibilizados na internet. Um desafio de ordem técnica é como compatibilizar segurança com facilidade de acesso e uso (cf. Seção 2).

No que tange aos conteúdos, não se trata nesse caso necessariamente de algo que vá além do livro no sentido de um extra. Pelo contrário: cabem aqui também atividades tidas como centrais na abordagem proposta, sem que tenham, porém, de cumprir o papel de fonte para as seções de sistematização que constam do meio impresso. Dois exemplos seriam: 1) um texto mais complexo, seguido de tarefas de compreensão e mesmo interação em sala de aula; 2) uma variante cujo diferencial não seja a complexidade, mas sim o gênero do texto, direcionado quiçá a públicos específicos, como alunas dos cursos de Letras-Alemão ou de outras áreas etc. A grande vantagem de uma tal interface online é que pode oferecer atividades alternativas para diferentes cenários de aplicação, a serem utilizados - ou não - de acordo com as especificidades de cada contexto, ou com o programa enfatizado pela professora em determinado momento, como resposta a circunstâncias não previstas inicialmente (cf. Seção 3).

No mais, nesse espaço virtual não se colocam com a mesma intensidade as restrições relativas ao uso de fontes externas, posto que, na eventualidade de mudança ou mesmo supressão dessas fontes, o material pode ser atualizado para contemplar tais mudanças, ou mesmo substituído por outro, mais atual ou mais adequado às novas necessidades. Por outro lado, esse tipo de uso, para além de possibilitar a atualização, também exige que ela seja feita com alguma sistematicidade. Aqui se coloca a questão da própria comercialização do acesso aos materiais, que poderá eventualmente ser feita na forma de venda não apenas de um produto, como também de um serviço - a exemplo do que já ocorre com softwares de larga utilização comercial, provedores de acesso etc.

O círculo externo da Figura 1 aponta para a possibilidade de uma função de repositório de que remeta a outras fontes, sejam elas MDs ou materiais não 
Oliveira, P.; Ledel, L. - Zeitgeist. Modelando um projeto editorial

facilitados/didatizados, aglutinando referências com maior potencial de utilidade para o público-alvo do próprio projeto editorial, i.e., de um nicho específico formado por IESs públicas brasileiras, seja na formação de professoras em cursos de Letras-Alemão, seja no atendimento à comunidade acadêmica de modo mais geral - cujas necessidades não são total ou adequadamente contempladas pelos MDs globais de uso mais corrente no país. Em outras palavras: por se configurarem como uma alternativa ao mainstream, os MDs propostos não precisam concorrer com tudo aquilo que estiver bem resolvido no próprio mainstream. Tomemos como exemplo a preparação para os exames padronizados que seguem à risca as determinações do QUADRO, como os realizados pelo Instituto Goethe e outras fontes de certificação. Mas também existem demandas específicas, como as de aprendizes interessadas em linguagens de especialidade, para as quais pode haver material adequado já existente (como a série Bausteine de "alemão científico" patrocinada pelo DAAD nos anos 1990), sem que isso seja de conhecimento geral. Num certo sentido, portanto, esse círculo externo funcionaria como um portal de serviços para o qual não se coloca(m) a questão dos direitos autorais ou outras restrições de natureza semelhante.

Nas próximas seções, discutimos de forma mais aprofundada alguns aspectos específicos dessa proposta geral, levando em conta o cenário atual e uma prospecção das dinâmicas futuras, num formato que reflete o estágio corrente da discussão, com alguns tópicos mais bem delineados e outros ainda colocados como questões a serem equacionadas a seu devido tempo. A perspectiva adotada confere à concepção de ensinoaprendizagem e aos objetivos formativos clara prioridade diante da dimensão estritamente técnica, cabendo sempre também a pergunta sobre a exequibilidade no contexto de aplicação previsto.

\section{Interface virtual}

Descrevemos aqui - de forma mais detalhada, mas sem pretensão à exaustão - diversos aspectos técnicos relativos à implementação do sistema de suporte aos conteúdos digitais vinculados ao projeto editorial em tela. Abordam-se também as possibilidades técnicas e os múltiplos caminhos possíveis, relativos à criação do sistema, explorando seus desafios e consequências, bem como a quantidade de fatores e aspectos a serem levados em 
Oliveira, P.; Ledel, L. - Zeitgeist. Modelando um projeto editorial

consideração, a fim de obter-se, ao final do processo de desenvolvimento, o resultado esperado em termos de plataforma de software ligada ao projeto editorial.

\subsection{Conceitos de Arquitetura e Plataforma de Software}

A primeira etapa no processo de criação de uma plataforma de software, qualquer que seja, é a definição de sua arquitetura. Segundo Ian Sommerville,

uma arquitetura de software é uma descrição de como um sistema de software é organizado. As propriedades de um sistema, como desempenho, proteção e disponibilidade, são influenciadas pela arquitetura adotada. As decisões de projeto de arquitetura incluem questões ligadas ao tipo de aplicação, modelo de distribuição do sistema, estilo arquitetural e à forma como a arquitetura deve ser documentada e avaliada. (SOMMERVILLE 2011: 121)

A arquitetura de software também pode ser definida como um

conjunto de declarações, que descreve os componentes de software e atribui funcionalidades de sistema para cada um deles. Ela descreve a estrutura técnica, limitações e características dos componentes, bem como as interfaces entre eles. A arquitetura é o esqueleto do sistema e, por isso, torna-se o plano de mais alto-nível da construção de cada novo sistema. (KRAFZIG, BANKE, SLAMA 2004: 56)

Diversos padrões de arquitetura de software foram identificados e divulgados junto à comunidade de analistas e desenvolvedores de sistemas. Dentre eles, podem-se citar: Modelo-Visão-Controlador, Arquitetura em camadas, Repositório e Clienteservidor (SOMMERVILLE 2019). Descrever cada um desses padrões iria além do escopo do presente trabalho, porém citá-los já permite à leitora inferir a quantidade e complexidade de decisões a serem tomadas, quando da escolha de uma arquitetura de software para um determinado propósito.

Após a escolha da arquitetura de software mais adequada ao sistema, a próxima etapa é a escolha e/ou criação da plataforma de software que melhor atenda às definições do estilo arquitetural adotado. A plataforma, em termos computacionais, diz respeito ao conjunto de software e hardware que implemente - total ou parcialmente - uma determinada arquitetura de software. Como exemplos de plataformas de software podemse citar: Java EE, Microsoft .NET e LAMP - este último um acrônimo referente às primeiras letras de Linux (um dos Sistemas Operacionais mais seguros atualmente), Apache (Servidor confiável e de licença open-source), MySQL (um dos Bancos de Dados da Oracle) e PHP (linguagem de programação para a $W e b$ ). Do ponto de vista da cliente (a editora), a escolha da base computacional tem algumas implicações, no tocante ao tipo 
Oliveira, P.; Ledel, L. - Zeitgeist. Modelando um projeto editorial

de serviços que terá a seu dispor, que não se restringem a aspectos de natureza puramente técnica, abrangendo também dimensões de custo eventualmente distintas, dentre outros fatores.

\subsection{Conceitos básicos}

Após apresentados os conceitos de arquitetura e plataforma de software, pode-se voltar à discussão de como se pensa concretizá-la nos moldes necessários para o suporte do projeto editorial em desenvolvimento. Primeiramente, o modelo de acesso a recursos internos e externos do sistema - representado na Figura 1 - precisa ser suportado por meio de uma arquitetura de software que contemple as seguintes questões: a) Vínculo, por meio de QRCodes, de determinadas seções e/ou trechos do livro impresso a materiais adicionais, armazenados de forma digital na plataforma da editora; b) Criação de uma plataforma de software que permita o armazenamento, acesso e atualização de conteúdos digitais, com diferentes níveis de permissão - alunas (proprietárias do livro impresso), autoras e administradoras do sistema; c) Segurança no acesso aos dados e conteúdos armazenados digitalmente e relacionados ao material didático impresso; d) Questões técnicas relacionadas à performance do sistema digital, volume de acessos previstos, backups do sistema, possibilidade de evolução do mesmo, dentre outras a serem levantadas; e) Questões de acessibilidade, relativas a pessoas com necessidades especiais.

A plataforma de software a ser desenvolvida também apresenta diversas possibilidades de execução, que precisarão ser avaliadas com relação à melhor adequação aos objetivos propostos. Dentre as possibilidades já vislumbradas, destacam-se: a) Utilização de algum ambiente virtual de aprendizagem (AVA) ou sistema de gerenciamento de conteúdos (Content Management System - CMS) como base para o armazenamento dos materiais digitais previstos; b) Criação de uma plataforma nova, sem reuso de software de terceiros, e voltada aos objetivos do projeto; c) Uma solução híbrida, empregando tanto ambientes virtuais já existentes quanto novas unidades de software que, em conjunto, supram as necessidades do projeto. Como exemplos de AVAs destacam-se, dentre os gratuitos, o Moodle e o TelEduc, já mencionados acima. Ambos oferecem diversas ferramentas voltadas para o ensino, tais como armazenamento de conteúdos, chats, fóruns, mensagens, criação de tarefas, avaliações, dentre outras. Por outro lado, se o objetivo for apenas a disponibilização de conteúdos e quiçá também tarefas fechadas 
(tal como previsto para este projeto), poder-se-ia, alternativamente, utilizar algum CMS, como Wordpress, Joomla, Drupal ou TextPattern, dentre outros.

Resta saber se essa última opção não traria consigo algum tipo de desvantagem, posto que a escolha da plataforma a ser utilizada não é neutra, na medida em que afeta necessariamente a relação entre a editora e demais agentes envolvidas, como a equipe autoral, as prestadoras de serviço etc. O uso de um CMS, por exemplo, envolve formas de edição e publicação que demandam mais conhecimento técnico do que em AVAs (destinados ao ensino-aprendizagem). A opção por um CMS - ou software dedicado poderá garantir à editora um maior controle sobre os conteúdos. Uma forma de fazer isso seria limitar a permissão para modificações a uma prestadora de serviços especializada. Já o uso de AVAs poderá eventualmente facilitar à equipe autoral a atualização dos conteúdos. Esse último tipo de opção, por outro lado, implica que a relação entre equipe autoral e editora não se poderia se restringir à elaboração do produto, tendo de se estender, quiçá em contrato à parte, à manutenção de um serviço (de atualização). Na medida em que essa atualização for de interesse de ambas as partes, poder-se-ia ter aqui uma situação win/win que não envolva custos adicionais para a editora e, ao mesmo tempo, confira à equipe autoral maior autonomia para atualizar os MDs segundo as necessidades de suas potenciais usuárias.

\subsection{QRCode}

Agregamos aqui, de forma extremamente sucinta, alguns aspectos técnicos relativos ao QRCode (sigla já usada de modo reiterado acima, para referir-se a "código de acesso rápido" - do inglês Quick Access Response), indicando aplicações relevantes e sua importância para a plataforma de software que se pensa elaborar. Seu precursor é o código de barras que, na versão mais atual, constitui-se na representação gráfica unidimensional - na horizontal - de dados numéricos ou alfanuméricos. O QRCode diferencia-se do código de barras em inúmeros aspectos. Citaremos os mais relevantes para a compreensão de sua utilidade na plataforma de software aqui discutida. Em primeiro lugar, o QRCode é bidimensional (2D), contendo informações tanto no plano horizontal quanto vertical permitindo assim uma capacidade de representação de dados muito superior à do código de barras. Em segundo lugar, sua leitura também é diferente, podendo ser feita com a câmera de um smartphone. Outra característica é a capacidade de representar endereços da internet, tais como https://www5.usp.br/ (página de entrada do sítio virtual da USP) e 
https://www.dw.com/de/deutsch-lernen/s-2055 (página da Deutsche Welle, contendo materiais de estudo do idioma alemão).

Tais características tornam essa ferramenta uma escolha natural para a integração entre o universo real/material e o mundo virtual. E, naturalmente, justificam o seu emprego junto à plataforma de software descrita nesta seção. Retomando a relação entre o mundo empírico do livro e o virtual da internet, conclui-se que o $\mathbf{Q R C o d e}$ do livro e os links disponibilizados nos círculos interno e externo da Figura 1 têm exatamente a mesma função, a saber, remeter às mídias e páginas disponibilizadas para o público-alvo do projeto Zeitgeist. No trabalho com um dispositivo móvel (tablet ou smartphone), o acesso a essas referências será feito via leitura dos QRCodes disponíveis no livro. O computador, por sua vez, com tela maior e outros recursos de entrada de dados, fornecerá acesso preferencial provavelmente via links na tela do navegador.

\subsection{Requisitos funcionais e não-funcionais do sistema}

Algumas das etapas de desenvolvimento de um sistema computacional, como as definições de arquitetura e plataforma de software, foram descritas em 2.1 e 2.2. Há também um outro conceito - ainda não contemplado na discussão anterior - que é de extrema importância no desenvolvimento de sistemas e diz respeito aos requisitos funcionais e não-funcionais. Segundo Ian Sommerville,

os requisitos funcionais são declarações de serviços que o sistema deve fornecer, de como o sistema deve reagir a entradas específicas e de como o sistema deve se comportar em determinadas situações. Em alguns casos, os requisitos funcionais também podem explicitar o que o sistema não deve fazer. (SOMMERVILLE 2011: 59)

Ainda segundo Sommerville,

os requisitos não funcionais [...] não estão diretamente relacionados com os serviços específicos oferecidos pelo sistema a seus usuários. Eles podem estar relacionados às propriedades emergentes do sistema, como confiabilidade, tempo de resposta e ocupação de área. [...] Os requisitos não funcionais, como desempenho, proteção ou disponibilidade, normalmente especificam ou restringem as características do sistema como um todo. Requisitos não funcionais são frequentemente mais críticos que requisitos funcionais individuais. Os usuários do sistema podem, geralmente, encontrar maneiras de contornar uma função do sistema que realmente não atenda a suas necessidades. No entanto, deixar de atender a um requisito não funcional pode significar a inutilização de todo o sistema. Por exemplo, se um sistema de aeronaves não cumprir seus requisitos de confiabilidade, não será certificado como um sistema seguro para operar; se um sistema de controle embutido não atender aos requisitos de desempenho, as funções de controle não funcionarão corretamente. (SOMMERVILLE 2011: 60; destaque acrescido) 
No caso em tela, poder-se-ia elaborar como requisito funcional: "o sistema deve permitir o acesso da proprietária do livro impresso à respectiva plataforma digital". Ou, alternativamente, numa variante, mais específica: “o sistema deve permitir o acesso aos MDs da plataforma por meio de QRCodes impressos no livro". Como exemplos de requisitos não-funcionais do sistema, podem-se citar:

- o acesso à plataforma digital deve ser protegido de ataques do tipo DoS (Denial of Service, ou negação de serviço, em português) - requisito de segurança;

- o sistema deve possuir um segundo servidor, capaz de oferecer acesso aos dados, no caso de o servidor principal cair - requisito de robustez;

- o sistema deve ser de fácil utilização, permitindo o rápido aprendizado e a descoberta intuitiva de suas funcionalidades por parte das usuárias - requisito de usabilidade.

Alguns requisitos não-funcionais são mais fáceis de se atender que outros, e a necessidade de atender a mais de um ou a muitos requisitos não-funcionais simultaneamente pode tornar a tarefa de desenvolvimento mais complexa. Por exemplo, alguns recursos de segurança - como a autenticação de usuárias na entrada da plataforma online - pode comprometer em certa medida o requisito de facilidade de uso, no que tange ao acesso aos MDs contidos na plataforma. Exemplificando, a leitura de um QRCode de acesso à plataforma online - e a autenticação da usuária mediante a entrada de um login e uma senha - pode ser necessária antes de aceder aos MDs contidos na plataforma, o que atrasará, do ponto de vista da usuária, seu acesso a esses materiais. Por outro lado, o não atendimento ao requisito de segurança poderá eventualmente comprometer a usabilidade do sistema como um todo. Daí a importância de se encontrar um ponto de equilíbrio entre a arquitetura do sistema e as demandas de suas usuárias.

\subsection{Estágio atual \& reflexões decorrentes}

Nossa discussão até o momento trouxe à tona diversos aspectos relativos ao desenvolvimento da Interface Virtual do sistema, buscando não se abster de explicar conceitos importantes da área de Engenharia de Software e Computação em geral, necessários à compreensão dos termos utilizados no decorrer do texto, tais como arquitetura e plataforma de software, requisitos funcionais e não-funcionais, bem como 
Oliveira, P.; Ledel, L. - Zeitgeist. Modelando um projeto editorial

QRCodes. Muitas questões ainda precisam ser identificadas e trazidas para discussão, relativas ao desenvolvimento do sistema. Outras questões já levantadas, como o uso de QRCodes e a facilidade de acesso ao sistema, precisam ser mais bem compreendidas e incorporadas à arquitetura do sistema, e posteriormente implementadas por meio da plataforma de software.

A simples apresentação de todos os aspectos técnicos envolvidos na criação de uma plataforma virtual, como na breve descrição acima, já possibilita ter-se uma primeira ideia do quanto pode ser complexo um sistema computacional. Ao mesmo tempo, o sistema pode ser de fácil utilização, como as plataformas do Facebook, Twitter, WhatsApp, conforme já aludido na Seção 1. Quanto mais fácil e intuitiva for a utilização de um software - seja ele um aplicativo mobile (rodando no celular), um aplicativo para desktop (computador de mesa ou notebook) ou uma aplicação para a Web (que executa no ambiente de um navegador de internet, podendo ser acessada tanto no desktop quanto em um ambiente mobile) -, mais complexa será sua implementação, o que implica mais horas de trabalho e conhecimento técnico para sua realização.

Do ponto de vista da cliente que demanda tais serviços computacionais (a editora), isso significa maiores custos no desenvolvimento do sistema e, por consequência, um custo maior a ser repassado à usuária final, i.e., ao público-alvo de Zeitgeist. Por outro lado, a editora deve também levar em conta a sustentabilidade da plataforma digital, no que tange à atualização num universo digital em processo de mudanças vertiginosas. Sua plataforma atual, por exemplo, sustenta-se em HTML estático, o que permite a função de repositório, mas traz limitações a uma interação mais dinâmica no ambiente. Os AVAs mais correntes são programados em PHP, o que permite maior dinamismo e adaptações para uso em dispositivos móveis, apesar de uma programação feita originalmente para acesso web via desktops e notebooks. Já um software dedicado escrito em linguagem Java permitiria um uso independente do tipo dispositivo em mãos das usuárias finais. Mas a programação em Java é mais complexa do que em PHP, que é mais complexa do que em HTML estático - com todas as implicações de custo daí decorrentes. À questão do desenvolvimento propriamente dito se agrega ainda a necessidade de manutenção, envolvendo fatores como continuidade de acesso, sistema de backup etc., como mencionado acima. Levando isso em conta, a simples venda de um produto provavelmente não tornaria os MDs sustentáveis, do ponto de vista estritamente comercial, tornando-se então necessária a venda de um serviço a ser remunerado por 
determinado período, como nas licenças de software renováveis periodicamente tendência cada vez mais forte no universo digital. ${ }^{20}$

São esses alguns dos fatores de ordem técnica a serem levados em conta na produção de uma interface digital a ser incorporada num projeto editorial para o ensino de DaF, como Zeitgeist. Um outro desafio é como equacionar adequadamente a relação entre técnica e proposta didática, levando em conta os diversos contextos de uso previstos.

\section{Material didático como possibilidade ou restrição ${ }^{21}$}

Na Seção 1, colocamos a questão dos tipos de MDs com diferentes âmbitos de aplicação, caracterizados como globais, localizados ou locais, e registramos que a demanda articulada pela editora está inserida num contexto em que houve uma passagem gradual da utilização de MDs globais para localizados/regionais, aliada ao uso sistemático de recursos virtuais como suporte ao ensino-aprendizagem de alemão LE. A perspectiva agora é dar um passo adicional rumo à produção de MDs locais que atendam não só às necessidades da própria Unicamp, como também de outras IESs brasileiras, públicas ou não, nas quais haja demanda compatível. Portanto, para além da diferenciação entre um contexto mais amplo - internacional, com suas diferentes línguas e culturas - e a uma realidade nacional, marcada pelo português brasileiro como língua comum às aprendizes e uma certa homogeneidade cultural, há também de se levar em conta a enorme diversidade geográfica e social existente no país, assim como as especificidades das várias IESs públicas nas quais atuam os demais membros da equipe autoral.

\footnotetext{
${ }^{20}$ A onipresença de aplicativos como o WhatsApp exacerba a expectativa de que outros programas tenham a mesma imediatez e não representem custos (elevados) para a usuária. Tal facilidade de uso mascara a enorme complexidade tanto dos softwares em si quanto da infraestrutura de suporte necessária. O custo ausente/acessível só é possível em função da larga escala em jogo e do modelo de negócios por detrás desses aplicativos, mormente sustentado pela utilização dos dados da usuária no direcionamento da venda de outros produtos. É comum empresas inovadoras no mundo digital permanecerem deficitárias por vários anos, visando a conquista predatória do mercado (cf. UOL: https://bit.ly/3bybR1x; [30/03/2020]; ver também PARRA ET AL 2018). Tais estratégias não condizem com os propósitos e a dinâmica de uma editora acadêmica, que poderá, no máximo, contar com uma infraestrutura custeada pela própria IES (pública), onde o lucro não é um parâmetro central - configurando desde já importante diferencial face às editoras comerciais, mas sem eliminar todas as condicionantes de ordem pragmática, dentre elas sua escala limitada de produção, evidente num nicho restrito como MDs locais para DaF.

${ }^{21}$ O título desta Seção 3 dialoga com Alan Marley (2011), que discute em maior detalhe tópicos tratados aqui de forma concisa, remetendo também a Prabhu (1989).
} 


\subsection{Tecnologia, sociedade e educação}

Um primeiro aspecto a ser levado em conta é de natureza tanto técnica como social, na medida em que diz respeito aos fatores envolvidos no conceito de fosso digital: como tornar produtivo o uso de tecnologias, levando em conta a inexorável passagem para o virtual, sem com isso aumentar o efeito das diferenças socioeconômicas no acesso à educação? Em sua discussão dos desafios colocados por projetos de inclusão digital no Brasil, Claudia Prioste e Darcy Raiça (2017) sumarizam:

A correlação entre exclusão social e digital tem sido reafirmada por diversos pesquisadores, como: Almuwil, Weerakkody e El-Haddadeh (2011), Kaplan (2005), Livingstone e Helsper (2008) e Mancinelli (2007). Para Kaplan (2005), não obstante o intenso crescimento e penetração das TIC [Tecnologias de Informação e Comunicação] em todos os grupos sociais, o fosso digital ainda permanece enorme devido principalmente à heterogeneidade de usos realizados por grupos socioeconômicos distintos. Mancinelli observa que: "não há um fosso digital, mas múltiplos fossos, os quais estão relacionados a uma variedade de fatores tais como: gênero; idade; agrupamentos étnicos; incertezas de vida e condições financeiras; bem como insegurança social e no trabalho" (2007, p. 2, tradução nossa). Na perspectiva de Livingstone e Helsper (2008), as barreiras para inclusão digital são graduais e estão fortemente associadas aos processos de exclusão no seio da sociedade, confirmados por diversos estudos demonstrando que os indivíduos com maior acesso às TIC tendem a possuir maior escolaridade, maior renda e status profissional do que aqueles que não possuem acesso. Nesse mesmo sentido, Almuwil, Weerakkody e El-Haddadeh (2011) argumentam que o debate sobre o fosso digital não deve ser concebido meramente como falta de acesso ou de uso das tecnologias. (PRIOSTE \& RAIÇA 2017: 5-6)

No que tange ao contexto educacional brasileiro, as autoras argumentam que "importantes desigualdades são engendradas em decorrência do baixo ou do inadequado investimento em infraestrutura tecnológica nas escolas públicas" (p. 10). Por outro lado, ressaltam também que a discussão não deve se restringir à dimensão tecnológica, e elencam sete fatores a serem levados em conta, a começar pelos " $5 \mathrm{Cs":} \mathrm{1)} \mathrm{conectividade;}$ 2) capacitação; 3) conteúdo; 4) confiança e 5) continuidade, aos quais agregam dois outros: 6) proficiência em leitura e escrita; 7) educação inclusiva (PRIOSTE \& RAIÇA 2017: 6-7). Embora a discussão em pauta diga respeito ao contexto educacional mais amplo, notadamente no âmbito escolar, o raciocínio também se aplica, mutatis mutandis, ao âmbito das IESs públicas, na medida exata de sua inserção no sistema educacional como um todo, também no que concerne a variantes regionais e locais.

Cabe, portanto, refletir sobre o papel que os MDs propostos podem vir a exercer nesses contextos de aplicação. No que tange ao uso de tecnologia, coloca-se a questão já aludida mais acima, de que nem sempre o público-alvo dispõe de condições ótimas para acessar conteúdos digitais online. No entanto, parte dos problemas existentes para cursos 
total ou parcialmente online nos quais se queiram mobilizar atividades ou ferramentas que exijam mais recursos técnicos e de conectividade, etc. - como interação simultânea em vídeo e/ou outros tipos de comunicação síncrona - não se coloca da mesma forma para os MDs em si, dos quais não se deve esperar a proposição de atividades abertas, notadamente interativas, mesmo pelas vias disponíveis nos AVAs: fóruns, mensagens e avaliações, dentre outras. A implementação desse tipo de atividade dependerá antes das condições materiais e humanas dadas in loco, abrangendo desde a infraestrutura disponível até a cultura de ensino-aprendizagem e a capacidade de resposta das agentes envolvidas. Mas tudo aquilo que for disponibilizado em formato digital pelos MDs deverá ser passível de uma utilização com baixo uso de tecnologia e, sobretudo, não poderá ser dependente de conexões de internet estáveis e de grande velocidade. Isso implica que, para além da possibilidade de baixar para usos offline as mídias disponíveis online, os recursos digitais - sirvam eles de suporte para atividades em sala de aula ou de estudo autônomo - devem também contemplar uma versão para impressão. No caso de tarefas eletrônicas, que numa versão originalmente impressa viriam num caderno de exercícios ou integradas ao livro do curso, a passagem de volta - do virtual para o empírico demanda a confecção de uma versão adaptada, com layout específico para impressão e a disponibilização das respectivas chaves de correção. Retomando as exigências articuladas por Dietmar Rösler (2010: 78-79) no trecho citado em 1.3, trata-se, então, de usar os canais digitais para aprimorar as formas de trabalho, não podendo tais recursos tornarse barreiras para quem porventura tiver dificuldades de acesso a eles. Daí decorre, para o projeto editorial Zeitgeist, a exigência de que, ao preservar as diversas funções dos MDs, seja mantida também a possibilidade a restaurar a forma material (meio impresso; $m p 3$ ou $m p 4$ para uso local) quando e onde isso se fizer necessário.

\subsection{Diversidade \& convergência}

A questão da possibilidade/necessidade de diferenciar as formas de trabalho para contemplar a diversidade existente no universo de atuação, seja uma sala de aula, seja um público leitor ou uma audiência indiscriminada, não é nova, cabendo também aqui assinalar sua inserção em toda uma tradição discursiva.

Nos meios digitais, uma tal diferenciação é atingida pelo recurso do hipertexto, que permite abordar os mesmos tópicos via referências múltiplas, visando o aprofundamento, a remissão a discussões paralelas ou a outras mídias etc. Essa já era uma 
das funções das notas finais ou de rodapé e do sistema de citações em textos escritos, antes mesmo do advento do hipertexto digital. Nesse sentido, a ideia de hipertexto é anterior à sua versão digital contemporânea, habitando mesmo o próprio conceito de texto enquanto tessitura de diversas linhas que se entrecruzam para formar um todo, que pode ser múltiplo e aberto - mas abriga necessariamente um algo, algum padrão que lhe confira certa identidade própria. O modelo sintetizado na Figura 1 certamente se configura como hipertexto com uso de tecnologias digitais, tanto na passagem do livro impresso à plataforma da editora via QRCode quanto nos diversos links previstos para os círculos interno e externo dessa plataforma, independentemente do formato em que vier a se concretizar, i.e., se AVA ou CMS, se com programação em HTML estático, PHP ou Java etc.

No universo do ensino de DaF, uma questão surgida nas últimas décadas diz respeito à necessidade de se lidar com a heterogeneidade eventualmente existente em determinado grupo de aprendizes, de modo a contemplar, por exemplo, o potencial e os limites do que se deixa fazer a partir de um ou diversos insumo(s) - como um ou diferentes texto(s) para a mesma turma. O princípio da diferenciação interna (Binnendifferenzierung) se coloca sobretudo em situações clássicas de ensino presencial com grupos heterogêneos, mas também se aplica a variantes virtuais e pode ser levado em conta na confecção de MDs (TÖNSHOFF 2004, 2005; DEMMIG 2008; AlTRICHTER ET AL. 2009; ASCHEMANN ET AL. 2011; HERZIG ET AL. 2017). ${ }^{22}$ Um aspecto importante nessa discussão é que diferenciação pressupõe uma carga adicional de trabalho, para cuja execução as condições reais em muitos contextos concretos não contribuem. Para nossos propósitos, vale resgatar algumas observações de Wolfgang Tönnshoff, no tocante a currículos e materiais didáticos:

Se os currículos de LE não fizerem pelo menos uma distinção entre fundamentum (para todos os objetivos e conteúdos obrigatórios) e additum (objetivos e conteúdos adicionais), as possibilidades de diferenciação interna ficam desde já relativamente limitadas [p. 13; ...]. MDs para ensino de LE que contêm ofertas para diferenciação interna podem compensar parte do esforço adicional [da professora, para implementar a diferenciação]. Uma solução simples, mas claramente efetiva, consiste-se de um conjunto de textos e materiais adicionais ("baú de achados" [Fundgrube], compilações de materiais etc.), dos quais a professora pode se servir para as fases de diferenciação da aula e, dentre outros, também para criar tarefas alternativas que diferenciem o trabalho nas fases abertas de aprendizagem [p. 15]. (TÖNSHOFF 2005: 13, 15)

\footnotetext{
${ }^{22}$ Ver também https://deutsch-lernen.zum.de/wiki/Binnendifferenzierung.
} 
Oliveira, P.; Ledel, L. - Zeitgeist. Modelando um projeto editorial

Hipertexto e diferenciação interna convergem com a ideia de harmonizar, numa mesma proposta editorial, materiais que estejam no núcleo de um curso ou the sirvam de complemento (ou alternativa), como mormente ocorre seja nas variações ad hoc das professoras, na incorporação de diferentes títulos às ementas de disciplinas ou mesmo via oferta editorial (kurstragend vs. kursbegleitende Materialien) - ainda que nesses casos não se tenha o grau de organicidade previsto nas propostas do pós-método discutidas brevemente na próxima Subseção (3.3). O modelo em tela parte do princípio de que é preciso ter um fio condutor que permita a professoras com pouca disponibilidade para a preparação de aulas e aprendizes eventualmente sobrecarregadas com outros compromissos avançar no programa de forma clara e segura, garantindo um patamar mínimo que possa ser compatibilizado com exigências externas, tais como parâmetros curriculares, certificações etc. Por outro lado, é preciso oferecer possibilidades de variação de acordo com as condições locais, respeitando também o princípio da autonomia da professora e da aprendiz.

Na medida em que o livro didático tem uma forma material mais perene e servirá como referência para os componentes destinados à sistematização, envolvendo gramática, vocabulário, funções de linguagem e quaisquer outros parâmetros que se queira apresentar de forma concisa ou usar como critério organizador, cabe a ele, prioritariamente, a função de aglutinar os elementos, formando um fio condutor para o curso (núcleo na Figura 1). Já a plataforma virtual da editora (sobretudo círculo interno na Figura 1), independentemente de seu formato, cumprirá prioritariamente a função de oferecer alternativas adequadas à diferenciação local, de acordo com o público-alvo específico, reforçando a possibilidade de escolhas - ainda que parte desses materiais exerça também uma função também central na abordagem proposta, conforme já mencionado em 1.3.

3.3 Fio condutor \& Flexibilidade: conceitos-chave para empoderar (sem sobrecarregar) a professora

O conceito de autonomia da aprendiz faz-se presente na área de DaF desde os anos 1980 e orienta substancialmente os diversos paradigmas surgidos desde então. Menos destaque tem a noção de autonomia da(s) professora(s) (Autonomie der Lehrenden). Alguns dos trabalhos já citados no presente ensaio lidam com essa questão, razão pela qual serão 
Oliveira, P.; Ledel, L. - Zeitgeist. Modelando um projeto editorial

usados como referência preferencial a seguir, para não abrimos demasiadamente o leque do debate.

$\mathrm{Na}$ análise do conceito de método e sua relação com MDs para o ensino de línguas, Mariana Kunz de Andrade e Silva retoma algumas autoras que se debruçaram sobre o tema e registra uma postura bastante disseminada, segundo a qual

[t]eóricos criam conhecimento, e professores são apenas consumidores: para Kumaravadivelu [2006], o conceito de método sustenta a dicotomia entre teoria e prática, transformando o pesquisador em produtor de conhecimento e o professor em consumidor, uma relação indesejavelmente hierárquica e comercial, que contribui para a falta de diálogo entre estes profissionais. (ANDRADE E SILVA 2016: 50)

Na sequência, a autora remete à discussão sobre os MDs na área de DaF:

Livros didáticos tentam concretizar e tornar precisas as ideias e os princípios dos métodos de ensino de tal forma que originam um conceito de aula bem específico. [...] Não é coincidência que em alguns países e línguas os conceitos "livro didático" e "método" sejam usados como sinônimos. (NEUNER \& HUNFELD, 1993: 16 apud ANDRADE E SILVA 2016: 50)

Por "conceito de aula bem específico" entende-se mormente uma visada relativamente única, fechada - apesar de toda diferenciação e possibilidades de abertura sugeridas por MDs mais recentes. No contexto do uso de MDs globais, tal conceito específico de aula (Unterricht) implica também assumir uma perspectiva top-down, adotando um olhar oriundo da discussão em curso nos lugares onde são produzidos esses MDs (Kumaravadivelu 2006: 165, 182). Levando isso em conta, foi até mesmo sugerido que descartemos próprio conceito de método, num debate que levou à noção de condição pós-método de Kumaravadivelu ([1994] 2006: 161-162, 170-183 [Cap. 8.2], passim). Os argumentos da visada pós-método são pertinentes, sobretudo naquilo que enfatizam a necessidade de se incorporar à discussão e à prática didática uma perspectiva bottom-up, da cultura local, com uma miríade de agentes e fatores envolvidos.

Mas há também o risco de se pensar o prefixo pós- como abandono ou negação radical de algo que se tornara por demais dominante - num movimento de pêndulo que, ao invés de dissolver uma dicotomia, acabe apenas privilegiando o polo oposto ao que se combatia. Tomemos, como exemplo, o conceito de pós-estruturalismo que, a rigor, não significa um abandono do estruturalismo, mas sim que a estrutura agora é compreendia como multicêntrica, sendo o fechamento do sistema (ou conceito) apenas virtual. No nosso caso, seria importante não entender o pós-método como espaço de um ecletismo desordenado e sem rumos, que entronizasse a prática imediata - como se ela prescindisse 
Oliveira, P.; Ledel, L. - Zeitgeist. Modelando um projeto editorial

de reflexão (para dizer o mínimo): "Se por ecletismo se entende o uso aleatório e conveniente de qualquer técnica que venha com mais facilidade, então ele não tem mérito algum" (WIDDOWSON 1990: 50 apud KUMARAVADIVELU 2006: 169). Nesse sentido, o caminho mais promissor não é deixar de assumir uma visão própria, nem questionar o uso de MDs tout court ${ }^{23}$, mas antes incorporar aos materiais um "conceito de aula" que seja aberto e flexível, mas não sugira um laissez-faire eclético que passe ao largo do reconhecimento de que toda prática pedagógica sustenta-se - necessariamente - numa concepção de linguagem e de ensino-aprendizagem, sejam essas respectivas concepções explicitadas ou não. Daí também a necessidade de explicitarmos nossas premissas teóricas.

Podemos aqui retomar o debate sobre a oposição top-down vs. bottom-up realizado em outro contexto (dos chamados "cursos instrumentais" de leitura), no tocante à natureza da compreensão - se do todo para as partes ou das partes para o todo - e resgatar também para a questão dos MDs uma terceira via: uma abordagem integrada, que leve em conta tanto o fator top-down como o bottom-up, colocando-os numa relação dialógica (ESKEY 1988). Note-se que ambos movimentos fazem parte do conceito de círculo hermenêutico mobilizado por pensadores como Friedrich Schleiermacher, Hans-Georg Gadamer e toda uma tradição filosófica. A tarefa básica continua a ser, como já aludido no início deste trabalho, a busca por respostas locais a questões postas de modo global. No tocante ao olhar local, e levando em conta a experiência anterior com Die Suche, podemos resgatar o que já dizia Michael Schart:

Quem ensina também pode usar um olhar sistemático e autocrítico para pesquisar suas próprias ações e os vários fatores de influência no ensino. [Ao fazer isso], não apenas cria uma base para uma melhor compreensão e desenvolvimento de seu ambiente de trabalho imediato, mas também dá uma importante contribuição para a ciência, com sua perspectiva específica. (SCHART 2005: 7; cf. também KUMARAVADIVELU 2006: 173)

Não cabe aqui maior aprofundamento sobre as implicações, teóricas e práticas, da discussão em pauta, mas vale registrar que o modelo sintetizado na Figura 1 procura, de um modo ou outro, dar conta dos três parâmetros elencados por Kumaravadivelu para o planejamento do ensino de LE na condição do pós-método: particularidade, praticabilidade e possibilidade (KUMARAVADIVELU 2006: 171-174 [Cap. 8.2.1]). Para Zeitgeist, a tarefa de vincular os MDs a seu ambiente imediato de aplicação fica

\footnotetext{
${ }^{23}$ Cf. Subseção 1.2 (n.10) para rol de problemas em experiência institucional concreta com trabalho sem
} MDs. 
Oliveira, P.; Ledel, L. - Zeitgeist. Modelando um projeto editorial

extremamente facilitada pelo fato de que a equipe autoral está integrada ao universo de professoras a que eles se destinam (particularidade). ${ }^{24} \mathrm{Com}$ isso, fica potencialmente suspensa a dicotomia entre teoria e prática, pensadoras e consumidoras. Tal suspensão, por si só, já traz em seu bojo um vasto potencial para o empoderamento da professora (MALAY 2011), como um dos resultados da autonomia que conquistar. Ao discutirmos a dimensão mais técnica/comercial na elaboração de MDs locais para o ensino de $\mathrm{DaF}$, foi dito que o foco num nicho muito específico coloca algumas restrições, sobretudo de escala (Seção 2, n.20). No tocante à metodologia, por sua vez, a especificidade do nicho é antes um facilitador do que um complicador. Alguns dos fatores relevantes são: público universitário composto por estudantes de Letras-Alemão e/ou dos demais cursos de uma IES; possibilidade de uso do português como metalinguagem, com espaço para uma abordagem contrastiva; vínculo com uma editora universitária, com eventual possibilidade de atualização constante dos materiais.

A ideia de que as necessidades específicas de um público universitário são diversas daquelas de quem quer ou deve utilizar uma LE para turismo ou negócios, ou mesmo em contextos escolares, não é necessariamente nova ${ }^{25}$, mas só recentemente veio a receber maior atenção na área de DaF no Brasil (UPHOFF ET AL. 2017, 2019). Tendo em vista o interesse renovado pelo assunto, torna-se plausível abordar os MDs sob a perspectiva apontada por Michael Schart: "sobretudo como um serviço de preparação para o ensino e como um companheiro para os processos de ensino e aprendizagem" (SCHART 2005: 8 [remetendo a Funk 2001: 290]) - atenuando-se os efeitos da observação que vem a seguir: "No entanto, na medida em que [os MDs] dominam o cenário, limitam o profissionalismo de quem ensina e colocam sob tutela [entmündigen] todas as partes envolvidas" (ibid.).

A retomada do debate sobre as especificidades no ensino de LE em contextos universitários, aliada à discussão feita até aqui no presente trabalho, sugere existir agora um horizonte propício para implementar, na prática, alguns dos preceitos preconizados em propostas críticas ao mainstream. A oposição course vs. source materials sugerida

\footnotetext{
${ }^{24}$ Sobre a praticabilidade, vide discussão dos aspectos técnicos (Seção 2) e de questões sociais (Subseção 3.1). O interesse da Editora da Unicamp em produzir um livro texto destinado ao ensino de DaF em IESs brasileiras representa certamente uma possibilidade real de implementar propostas didáticas condizentes. Note-se, de passagem, que o termo "livro didático" não se aplica, no mercado editorial brasileiro, a contextos universitários - sem prejuízo da expressão "materiais didáticos" (MDs) mobilizada em nossa discussão ( Lehrwerke).

${ }^{25}$ Cf. I Colóquio de Ensino de Língua Estrangeira em Contexto Universitário (I CELE) - Unicamp, 2004.
} 
por Prabhu (1989) pode ser mobilizada para tais fins, ainda que com alguns ajustes. Retomamos, a seguir, parte da síntese feita por Dörthe Uphoff (2009), levando em conta que os textos originais do linguista aplicado indiano continuam a ser de difícil acesso ao público leitor brasileiro. ${ }^{26}$

Uphoff (2009) considera que o "conservadorismo dos livros didáticos de DaF pode ser atribuído [...], pelo menos em parte, à visão negativa das editoras a respeito do saber-fazer e o poder-fazer do professor de línguas", corroborada pelo "comportamento do próprio mercado de ensino de DaF", no qual não se aceitam "propostas alternativas e inovadoras" como as dos MDs Die Suche e Dimensionen, levando então à perpetuação de "um modelo tradicional de livro didático, que dirige fortemente as ações do professor" e reforça "uma visão de professor como um profissional com pouca qualificação e disponibilidade para experimentar outras formas de ensino e assumir um papel mais autônomo na condução de suas aulas" (UPHOFF 2009: 97-98). É como uma possibilidade de questionar a "hierarquia de saberes entre o autor de livro didático e o professor" (p. 105) que Uphoff remete então aos assim chamados discursos de resistência (pp. 105-109) e sugere a adoção de uma "concepção alternativa de qualidade (p. 106) informada pelo linguista aplicado indiano, o qual "advoga uma série de mudanças na configuração" dos MDs, "no intuito de possibilitar um manuseio mais livre dos textos e atividades que esses materiais oferecem [Prabhu 1988: 7]". MDs tradicionais recebem então o rótulo de "material de curso" (course material), reservando-se para o modelo alternativo proposto o rótulo de "material-fonte" (source material):

Materiais-fonte (...) são aqueles que fornecem um conjunto de insumos possíveis, sem pretender que todos esses insumos sejam usados em todas as salas de aula ou que em todas as salas de aula sejam usados os mesmos insumos. Eles (= os materiais-fonte) podem sugerir diferentes agendas de ensino e formatos de aula, porém, não são, eles mesmos, organizados em unidades de aula. Eles podem prover insumos em diferentes níveis de dificuldade e em diferentes quantidades, deixando para o professor a tarefa de escolher os insumos nos dois sentidos. ([Prabhu 1988: 7] apud UPHOFF 2009: 97; destaques acrescidos) ${ }^{27}$

Essa proposta de uma outra configuração de MDs, mais flexíveis e adaptáveis a diferentes "agendas de ensino e formatos de aula", chegou à discussão das iniciadoras do projeto Zeitgeist relativamente cedo, num momento em que começava a tomar corpo a

\footnotetext{
${ }^{26}$ Daí o recurso a uma versão não publicada: Prabhu, N. S. Materials as support, materials as constraint. Singapore: RELC Seminar, 1988 (mimeo).

${ }^{27}$ Grafamos os colchetes originais [...] na forma de parênteses (...), reservando para interpolações nossas o uso de colchetes, notadamente para informar as fontes citadas pela autora.
} 
própria constituição de uma equipe autoral mais ampla e se buscavam critérios norteadores para o trabalho conjunto (UPHOFF 2019a-b). Se tomarmos a distinção articulada por Prabhu no plano teórico não como uma dicotomia rígida e estática, mas antes como possíveis elementos de um modelo multimodal integrado e flexível, não será difícil chegar a uma proposta concreta como a sintetizada na Figura 1. O ajuste aludido acima, de modo semelhante ao que foi argumentado quanto à noção de pósmétodo (Kumaravadivelu 2006), consiste em substituir uma dicotomia (tese vs. antítese) por uma síntese, num modelo que integre source \& course materials. Daí advém a estratégia, descrita em 1.3 e retomada em 3.2, de garantir via livro impresso uma linha de trabalho claramente definida, que possa servir de porto seguro para professoras que trabalhem em contextos menos favoráveis, seja em decorrência de condições macroestruturais de longo prazo ou de inflexões circunstanciais passageiras.

Mas os ajustes dessa síntese não se limitam a uma harmonização com a ideia de manter o livro como fio condutor, posto que a dimensão digital possibilita também movimentos rumo a uma radicalização da proposta de empoderamento da professora. Trata-se não apenas de entender que nem todos insumos precisam ser "usados em todas as salas de aula ou que em todas as salas de aula sejam usados os mesmos insumos", mas também de abrir espaço para que novos insumos, produzidos localmente, possam vir a ser usados em outros locais e por outras professoras - se adotado o caminho das atualizações constantes caracterizado em 2.2 como situação win/win para a editora e a equipe autoral. Em outras palavras: além de oferecer caminhos alternativos ou complementares ao fio condutor para uso onde isso for possível e adequado, a via digital, ao contemplar eventuais atualizações, não só possibilita uma estratégia de sustentabilidade temporal, como também favorece formas colaborativas de trabalho - no âmbito do empoderamento da professora. Tal ideia talvez seja por demais utópica, mas utopias são, de algum modo, também necessárias. O que não deve acontecer é torná-las condição sine qua non, inviabilizando o trabalho se não concretizadas.

Retomando a questão da diferenciação interna tratada em 3.2, lembre-se que ali estão em jogo atividades diversas para um mesmo grupo, ao passo que o conceito de source materials remete a materiais que contemplem diferentes agendas no uso com grupos distintos, agregando-os, porém, numa mesma compilação - que seja flexível o suficiente para permitir tal variação de uso. ${ }^{28}$ Como potencial para tais agendas variadas,

\footnotetext{
${ }^{28}$ A citação de Tönshoff $(2005: 13$, 15) acima sugere uma certa linha de continuidade. Se tomarmos o
} 
Oliveira, P.; Ledel, L. - Zeitgeist. Modelando um projeto editorial

têm-se no modelo sintetizado na Figura 1 o ensino de DaF para Letras-Alemão ou aberto a outros cursos nas IESs brasileiras, com inúmeras variações locais e regionais etc. Apesar de toda a diversidade envolvida, trata-se de um universo incomparavelmente mais homogêneo do que o visado por MDs globais.

No entanto, cabe também lembrar que, por mais representativa que seja a equipe autoral, ela não contempla todo o universo de professoras envolvidas com o público-alvo. Integrar ao modelo de Zeitgeist uma forte componente de flexibilidade é crucial, por diferentes motivos: 1) na elaboração dos materiais, facilita encontrar o maior denominador comum a ser integrado ao fio condutor, com o qual dialoguem diversas alternativas que visem contemplar variantes locais; 2) do ponto de vista conceitual, evita que a equipe autoral simplesmente passe da condição de consumidora à de criadora de conhecimento, nos termos da oposição questionada no discurso acadêmico crítico - mantendo como mera consumidora quem não for também autora; 3) no tocante à viabilidade econômica, permite alargar o universo do público contemplado; 4) dá maior sustentabilidade temporal ao projeto, sobretudo se devidamente explorado o potencial dos recursos digitais.

Não cabe aqui uma análise rigorosa das razões do insucesso comercial de MDs globais alternativos para $\mathrm{DaF}$, mas alguns aspectos já aludidos tornam plausível a hipótese de que, no caso de Dimensionen, a falta de um fio condutor mais nítido - para contextos que o demandassem - pode ter sido um dos fatores determinantes para a frustração das expectativas de que esse MD viesse a ser uma via de implementação mais ampla de preceitos da discussão teórica em DaF. ${ }^{29}$ Já na experiência brasileira com Die Suche relatada em 1.2, um fator problemático foi a amarração da progressão a um eixo narrativo único, no livro do curso, limitando assim o escopo das variações possíveis. $\mathrm{O}$

\footnotetext{
público-alvo de Zeitgeist como um grupo, vê-se uma proximidade ainda maior entre diferenciação interna e source materials.

${ }^{29}$ Num certo sentido, pode-se dizer que algo semelhante ocorreu com Deutsch aktiv (Langenscheidt) nos primórdios da abordagem comunicativa: a flexibilidade do MD em si e as demandas de autonomia que colocava para professoras e alunas revelaram-se quiçá excessivas, dificultando uma consolidação mais perene no mercado editorial. Parte do sucesso de Themen (Hueber), por outro lado, deixa-se explicar pela facilidade de uso, ao não se demandar grande autonomia das usuárias. No caso brasileiro, a autonomia é algo a ser conquistado a duras penas, apesar de contextos e tradições de ensino-aprendizagem não favoráveis, não podendo ser colocada como pressuposto idealizado - pois isso fatalmente levaria a frustrações (OLIVEIRA 2004, 2011, 2015).
} 
que se procura agora é resgatar o espírito de um MD local que certamente fugirá ao mainstream, mas não deve perder de vista as restrições colocadas pelos potenciais contextos de aplicação.

Dado o caráter multimodal do modelo proposto, cabe ainda retomar Uphoff (2009) sobre a integração de tecnologia digital às práticas de ensino, ressaltando três vias em evidência: 1) "um banco de dados centralizado e em constante expansão (RÖSLER 1999: 193 apud UPHOFF 2009: 107); 2) materiais compilados na internet e organizados localmente, nas diversas instituições (EDMONDSON 1999: 56 apud UPHOFF 2009: 107); 3) "sites de apoio elaborados pelas editoras destes materiais (= os livros didáticos convencionais na área de $\mathrm{DaF}$ ) e sites independentes com ofertas de materiais didáticos baseados apenas em recursos online" (WEININGER 2001: 58-59 apud UPHOFF 2009: 108). A autora destaca o recurso ao hipertexto como elemento comum a essas sugestões, lamentando, por outro lado, que tais propostas fiquem "mais no plano das ideias" e que haja "poucas iniciativas por parte das editoras de desistir do livro como elemento central de um material de curso" (ibid.).

No tocante à sua componente virtual, o modelo aqui proposto procura implementar, de modo orgânico, uma série de soluções que, segundo Uphoff (2009), estariam antes restritas ao "plano das ideias" - e cuja incorporação parcial às práticas editoriais mais recentes é ainda bastante precária, podemos agregar. Uma das dificuldades para tais atualizações é justamente o caráter global dos MDs em pauta, o que dificulta enormemente um direcionamento mais orgânico. Nas discussões que precederam a proposta editorial de Zeitgeist, no CEL/Unicamp, houve um período - relativamente longo - de busca sistemática por novos materiais que pudessem substituir a contento Blaue Blume, mas os resultados foram claramente insatisfatórios. De resto, MDs globais recentes que agregam componentes virtuais tendem a simplesmente "repaginar" os livros tradicionais, desconsiderando ainda as limitações colocadas pelo fosso digital discutido em $3.1 .^{30}$

\footnotetext{
${ }^{30}$ Essa é uma das conclusões que extraímos do workshop Smart und Digital - ein Tool statt Lehrwerke im DaF-Unterricht?!, realizado no Instituto Goethe de São Paulo (maio 2019). Há também aplicativos populares e plataformas virtuais que privilegiam a tecnologia, passando ao largo da reflexão didática mais recente na área de DaF. Cf. https://bit.ly/3bUJmMc; https://bit.ly/2YdGQMZ; https://bit.ly/2VNlxQD. Outras possibilidades envolvem o uso de teleconferência, já explorado comercialmente na individualização do ensino, ou em projetos de teletandem que cabem também em contextos formativos. Por fim, há também os desdobramentos da substituição emergencial forçada das salas de aula por programas de videoconferência, no contexto da pandemia de Covid-19 (cf. nota 6, acima). Tais usos, no entanto, extrapolam o escopo de uma proposta editorial propriamente dita.
} 


\section{Considerações finais}

Nas discussões em curso na equipe autoral de Zeitgeist, ${ }^{31}$ uma série de outros aspectos relevantes já se descortinam no horizonte, não cabendo aqui nem os mencionar, posto que a presente exposição já extrapola os limites de espaço previstos e o projeto se encontra ainda numa fase inicial. Desdobramentos futuros certamente virão.

Quando do início da fase mais experimental do percurso institucional na Unicamp, descrito em 1.2, na passagem dos anos 1980 para 1990, a pesquisa didática em DaF (Sprachlehrforschung) ainda engatinhava no Brasil. Nesse meio tempo, formou-se toda uma geração de professoras-pesquisadoras, e o interesse pela área nos cursos de pósgraduação não cessa de crescer (UPHOFF; ARAÚJO 2019). Caberá sobretudo a essas novas gerações enfrentar o desafio de superar o fosso existente entre a pesquisa acadêmica crítica e a utilização generalizada de MDs globais mainstream no país, inclusive em contextos acadêmicos e até mesmo na formação de futuras professoras (cf. UPHOFF 2009: 112, n.80; Blume 2011: 56 apud UphOFF; ArAúJo 2019: 92, 94). Para isso, será necessário alinhar a reflexão teórica em $\mathrm{DaF}$ com uma postura que não perca de vista as condicionantes pragmáticas colocadas tanto para a produção editorial quanto para quem trabalha com o ensino de $\mathrm{DaF}$ em condições não ideais. ${ }^{32}$ A proposta editorial aqui descrita é um esforço conjunto nesse sentido. Espera-se que outras iniciativas dessa ordem e um debate orgânico do tema venham na sequência.

Como adendo, cabe registrar que a pandemia de Covid-19 mudou radicalmente o papel atribuído à virtualidade, também no setor da educação - com gestores públicos e interesses particulares elevando-a à condição de panaceia geral e indiscriminada. ${ }^{33}$ Nesse "novo normal", as tecnologias digitais colocam para quem valoriza a equidade social um dilema semelhante ao da esfinge na antiguidade: decifra-nos ou devoramos-te.

\footnotetext{
${ }^{31}$ Anisha Vetter, Norma Wucherpfennig e Paulo Oliveira (Unicamp); Dörthe Uphoff, Marceli Aquino e Mariana K. A. Silva (USP); Poliana C. Arantes (UERJ); Mergenfel A. Ferreira (UFRJ); Francisco G. S. Nogueira e Rogéria C. Pereira (UFC); Thiago V. Mariano (UFPR); Leandro Ledel (IFSP); Fabiana R. Araújo (projeto gráfico). Mais detalhes no diretório de Grupos de Pesquisa do CNPq: http://dgp.cnpq.br/dgp/espelhogrupo/529618.

$32 \mathrm{Na}$ área de Tradução, há muito o objeto de pesquisa não se restringe ao texto propriamente dito. Em abordagens como os Estudos Descritivos e a Sociologia da Tradução, diversos outros (f)atores que influenciam o processo tradutório são integrados à reflexão. Cabe talvez movimento semelhante nos estudos empíricos de DaF no Brasil.

${ }^{33}$ Vide, dentre outros, a exposição de Tel Amiel (2020) no Webinar Treffpunkt do DAAD realizado em 29/04/2020 (https://bit.ly/3d2n2jt; [14/06/2020]).
} 


\section{Referências bibliográficas}

Altrichter, Herbert; TrautMann, Matthias; Wischer, Beate; SOMMERAuER, Sonja; DoPPLER, Birgit. Unterrichten in heterogenen Gruppen: Das Qualitätspotenzial von Individualisierung, Differenzierung und Klassenschülerzahl. Nationaler Bildungsbericht $2009 \mathrm{Bd}$. Cap. 3. https://www.bifie.at/wp-content/uploads/2017/05/NBB2009_Band2_KapitelC3.pdf. $(25 / 03 / 2020)$

AMIEL, Tel. Educação aberta: Ética, privacidade e autonomia em tempos de crise. DAAD Webinar Treffpunkt: Mobilidade e cooperação acadêmica na era digital: potencialidades e desafios. daad.reflact.com/treffpunkt (29/04/2020).

ANDRADE E SILVA, Mariana Kuntz de. Textos autênticos, adaptados e semi-autênticos no ensino de alemão como língua estrangeira: reflexões sob a perspectiva da pedagogia pósmétodo e da aprendizagem como participação. São Paulo, FFLCH/USP, 2016 (Dissertação de Mestrado).

Aschemann, Birgit; GugleR, Petra; NiMMERfall, Maria; KÜSTENMACHER, Werner Tiki. Vierzig Wege der Binnendifferenzierung für heterogene LernerInnen-Gruppen. Graz: Frauenservice Graz, 2011. https://erwachsenenbildung.at/downloads/service/reader binnendifferenzierung heterogene gruppen.pdf $(25 / 03 / 2020)$

BOHUNOVSKY, Ruth. Alemão para brasileiros: projeto, produção e avaliação de um livro didático nacional. In: Bohunovsky, Ruth (Org.): Ensinar Alemão no Brasil. Contextos e Conteúdos. Curitiba, Ed. UFPR, 2011, p. 83-98.

Bolognini, Carmen; Bohunovsky, Ruth; Uphoff, Dörthe; Dietrich, Georg; OliveIRA, Paulo. Lehrwerke im DaF-Unterricht in Brasilien. VI Kongress der ABRAPA, USP 2008. http://www.abrapa.org.br/cd/pdfs/Bolognini-Carmen-DRS8-Podiumsdiskussion-Lehrwerke.pdf $(19 / 03 / 2020)$

DEMMIG, Silvia. Das professionelle Handlungswissen von DaZ-Lehrenden in der Erwachsenenbildung am Beispiel Binnendifferenzierung. Eine qualitative Studie. München, Iudicium, 2008.

ESKEY, D. E. Holding in the bottom: an interactive approach to the language problems of second language readers. In CAREL, P. L.; DEVINE, J.; ESKEY, D. E. (eds.): Interactive approaches in second language reading. Cambridge, Cambridge University Press, 1988, p. 93-100.

HERZIG, Katharina; BIEDERMANN, Anne; Peuschel, Kristina; WILKE, Valeria; WuCHERPFENNIG, Norma. Zielgruppenorientierung zwischen Standardisierung und Differenzierung: DaF an lateinamerikanischen Hochschulen. InfoDaF v. 42 n. 6, 2015, 591-627. (Versão eletrônica 2017: DOI https://doi.org/10.1515/infodaf-2015-0606; [02/04/2020])

JENKINS, Eva-Maria. Dimensionen - a definite keeper?! ÖDaF-Mitteilungen n.2, p.51-56, 2006.

Koller, Wilhelm. Philosophie der Grammatik. Vom Sinn grammatischen Wissens. Stuttgart, Metzler, 1988.

KRAFZIG, Dirk; BANKE, Karl; Slama, Dirk. Enterprise SOA: Service-Oriented Architecture Best Practices. Prentice Hall, nov. 2004.

Kumaravadivelu, B. Understanding Language Teaching: From Method to Postmethod. Mahwah (NJ), Lawrence Erlbaum, 2006.

LEDEL, Leandro Camara. Sistemas de Informação em Saúde: o atendimento aos requisitos de escalabilidade e disponibilidade. Revista Network Technologies, v. 4, p. 98-106, 2010.

LEDEL, L. C.; RICARTE, I. L. M. Gestão do Conhecimento aplicada a fins educacionais. In: World Congress on Technology Education, 2004, Santos - SP. Proceedings of the World Congress on Technology Education. Santos - SP, 2004. v. 1.

Pandaemonium, São Paulo, v. 24, n. 42, jan.-abr. 2021, p. 217-254 
LUCAS, Patrícia de Oliveira. Os materiais didáticos de inglês como língua estrangeira (LE) na prática de professores da escola pública: um convite à formação reflexiva ou à perpetuação do ensino prescritivo? São Carlos: UFSCar, 2016. (Tese de Doutorado)

MALEY, Alan. Squaring the circle - reconciling materials as constraint with materials as empowerment. In TomLinson, Brian (Ed.): Materials Development in Language Teaching. Cambridge/New York: Cambridge University Press, 2011, p. 379-402. (2 $2^{\text {nd }}$ edition)

NIED UNICAMP. TelEduc. Unicamp: Núcleo de Informática Aplicada à Educação, 1997-2017. https://www.nied.unicamp.br/teleduc/

OLIVEIRA, Paulo. Auch Zwerge haben klein angefangen: Großes und Kleines rund um den Computer im DaF-Bereich. DaFBrücke (Curitiba), Buenos Aires - Argentina, v. 2, n.2, p. 15$18,2000$.

Oliveira, Paulo. Fachsprachen und Internet im DaF-Bereich. Cadernos de Letras (UFRJ), Rio de Janeiro, v. 17, p. 79-89, 2001.

OliVEIRA, Paulo. Lokale Antworten auf globale Fragen. In: Germanistentreffen, 2001, São Paulo. Germanistentreffen - Tagungsbeiträge. Bonn, Deutscher Akademischer Austauschdienst (DAAD), 2002. p. 107-129.

Oliveira, Paulo. Deutsch Lernen und Lehren mit elektronischen Mitteln: von der alltäglichen Anwendung bis zum virtuellen Klassenraum. In: V Congresso Brasileiro de Professores de Alemão e II Congresso de Professores de Alemão do MERCOSUL, 2002, São Leopoldo, RS. Anais do V Congresso Brasileiro de Professores de Alemão e II Congresso de Professores de Alemão do MERCOSUL. São Leopoldo, Editora da Unisinos, 2003. p. 280-299.

OliveIRA, Paulo. Autonomia no Ensino/Aprendizagem de Línguas Estrangeiras. $9^{a}$ Conferência para Profissionais de Ensino de Lingua Estrangeira. São Paulo, SENAC, 2004. (Palestrante convidado).

OliveIRA, Paulo. À procura da flor azul no ensino da língua alemã. Projekt (Curitiba), v. 44, p. 13-23, 2006.

OliveIRA, Paulo. Aprendizagem Autônoma e Ensino Colaborativo de Alemão. In: II Colóquio de Estudos Germânicos „Mito e Magia“, 2007, Araraquara. Anais do II Colóquio de Estudos Germânicos, 2007.

OliveIRA, Paulo. Blaue Blume mit TelEduc: Blended Learning und Vernetzung (Kurzvortrag). In: VI. Brasilianischer Deutschlehrerkongress und I. Lateinamerikanischer Deutschlehrerkongress, 2008, São Paulo. Annalen des VI. Brasilianischen Deutschlehrerkongresses und I. Lateinamerikanischer Deutschlehrerkongresses. São Paulo, ABRAPA, 2008. http://www.abrapa.org.br/cd/pdfs/Oliveira-Paulo-DRS8-Blaue-Blume-TelEduc-Fertig.pdf $(08 / 03 / 2020)$

OliveIRA, Paulo. Graus de Interação no Espaço Físico e Virtual. In: Ucy Soto; Mônica Ferreira Mayrink; Isadora Valencise Gregolin. (Org.). Linguagem, educação e virtualidade Experiências e reflexões. São Paulo, Cultura Acadêmica, 2009. http://books.scielo.org/id/px29p/pdf/soto-9788579830174-10.pdf (08/03/2020)

OLIVEIRA, Paulo. Escrita em ambientes eletrônicos: colaboração e avaliação inter-pares no Moodle. Anais eletrônicos. IV Congresso Brasileiro de Linguística Aplicada. Rio de Janeiro, ALAB, 2011. http://www.alab.org.br/images/stories/alab/CBLA/ANAIS/temas/19 14.pdf. $(23 / 04 / 2020)$

OLIVEIRA, Paulo. Escrita em ambientes eletrônicos: colaboração e avaliação interpares no Moodle. In: IX Congresso Brasileiro de Linguística Aplicada, 2012, Rio de Janeiro. Anais eletrônicos do Congresso Brasileiro de Linguística Aplicada. Rio de Janeiro: ALAB, 2012. v. 1. p. 1-18. https://alab.org.br/wp-content/uploads/2012/04/19 14.pdf $(08 / 03 / 2020)$

OLIVEIRA, Paulo. Autonomia e parâmetros externos: incompatíveis? Recolocando a questão no âmbito do laboratório de avaliação do Moodle, na companhia de Wittgenstein. Revista

Pandaemonium, São Paulo, v. 24, n. 42, jan.-abr. 2021, p. 217-254 
Oliveira, P.; Ledel, L. - Zeitgeist. Modelando um projeto editorial

EntreLínguas, v. 1, p. 85-110, 2015. DOI: https://doi.org/10.29051/el.v1i1.8054 (08/03/2020)

Oliveira, Paulo; Wucherpfennig, Norma; VetTer, Anisha. Alemão para universitários: formas híbridas. Cadernos de Letras (UFRJ), v. 24, p. 59-84, 2008.

OliveIRA, Paulo; WuCHERPFENNIG, Norma. Passagem para o virtual: as novas mídias. In: Ruth Bohunovsky (Org.). Ensinar alemão no Brasil: contextos e conteúdos. 1ed. Curitiba, Editora da Universidade Federal do Paraná, 2011, p. 99-121.

PARRA, Henrique Zoqui Martins; CRUZ, Leonardo; AMIEL, Tel; MACHADO, Jorge. Infraestruturas, Economia e Política Informacional: o Caso do Google Suite For Education. Mediações - Revista de Ciências Sociais (Londrina) v. 23 n.1, Jan./Jun. 2018, p. 6399. DOI: 10.5433/2176-6665.2018.1v23n1p63 (Dossiê vigilância, controle e novas tecnologias)

PRABHU, N. S. Materials as support, materials as constraint. Guidelines: A Periodical for Classroom Language Teachers, v.11, n.1 p. 66-74, 1989.

Prevedello, Clarissa Felkl; Rossi, Wagner Soares; Costa, Antônio Carlos da Rocha. Direito Autoral na Produção de Materiais Didáticos para a Educação a Distância: reflexões para a utilização na era da informação. Revista Thema n.12 v.2, 2015. http://revistathema.ifsul.edu.br/index.php/thema/issue/view/11 (26/03/2020)

PRIOSTE, Cláudia; RAIÇA, Darcy. Inclusão digital e os principais desafios educacionais brasileiros. RPGE - Revista online de Política e Gestão Educacional, v. 21, n. esp. 1, p. 860-880, out./2017. DOI: http://dx.doi.org/10.22633/rpge.v21.n.esp1.out.2017.10457 $(22 / 03 / 2020)$

QUADRO Europeu Comum de Referência para as Línguas: Aprendizagem, Ensino, Avaliação. Conselho da Europa, 2001-. https://www.dge.mec.pt/quadro-europeu-comum-de-referencia-para-linguas $(19 / 03 / 2020)$

RÖSLER, Dietmar. E-Learning Fremdsprachen - eine kritische Einführung. Tübingen, Stauffenburg, 2010. (3. Auflage)

RÖSLER, Dietmar; WÜRFFEL, Nicola. Digitale Medien. In UlRICH, Winfried (Hrsg.): Deutschunterricht in Theorie und Praxis (DTP) 10 / OOMEN-WELKE, Ingelore; AHRENHOLZ, Bernt (Hrsg.): Deutsch als Fremdsprache. Baltmannsweiler: Schneider Verlag Hohengehren, 2017, p. 252-260.

SARTINGEN, Kathrin. OliveIRA, Paulo; Degelo, Ana Luiza Zink. Fernstudienkurse in Brasilien. Zielsprache Deutsch, v. 27, n.2, p. 92-97, 1997.

SCHART, Michael. Die Suche - ein Nachruf. Das ,andere Lehrwerk“ aus der Sicht japanischer Studierender. Zeitschrift für Interkulturellen Fremdsprachenunterricht v.10 n.2, 2005. https://tujournals.ulb.tu-darmstadt.de/index.php/zif/article/view/434/410 (24/03/2020)

SommerVILLE, Ian. Engenharia de Software. São Paulo, Pearson Education do Brasil, 2011. (9 Edição)

TÖNSHOFF, Wolfgang. Binnendifferenzierung im lernerorientierten Fremdsprachenunterricht (I). Deutsch als Fremdsprache v. 41 n.1, 2004, p. 227-231.

TÖNSHOFF, Wolfgang. Binnendifferenzierung im lernerorientierten Fremdsprachenunterricht (II). Deutsch als Fremdsprache v. 42 n.1, 2005, p. 13-17.

UPHOFF, Dörthe. O poder do livro didático e a posição do professor no ensino de alemão como lingua estrangeira. Campinas, DLA/IEL/Unicamp, 2009. [Tese de Doutorado]

UPHOFF, Dörthe. Zeitgeist: um projeto de livro didático para o ensino de alemão em contexto universitário. (Mesa: Ensino de língua alemã e pesquisa). III Congresso da ABEG "Travessias, Encontros, Diálogos". Niterói, UFF, 2019a. (http://germanistik-brasil.org.br/terceiro-congresso-abeg/programacao/)

UPHOFF, Dörthe. Deutsch in universitären Kontexten: Teilhabe und Förderung der Kritikfähigkeit als methodisch-didaktische Prinzipien. (Mesa: Aprender/Ensinar alemão em contextos

Pandaemonium, São Paulo, v. 24, n. 42, jan.-abr. 2021, p. 217-254 
Oliveira, P.; Ledel, L. - Zeitgeist. Modelando um projeto editorial

universitários: possibilidades e desafios do século XXI). DIPROLing2019. Campinas, Unicamp, 2019b. (https://www.cel.unicamp.br/diproling/index.php/pt/programacao-4)

UPHOFF, Dörthe. ARAÚJO, Fabiana Reis de. Historiografia de estudos brasileiros sobre o ensinoaprendizagem de alemão como língua estrangeira. In UPHOFF ET AL. (Orgs.): Alemão em contexto universitário. Ensino, pesquisa e extensão. São Paulo, FFLCH/USP, 2019, p. 79-102.

Uphoff, Dörthe; Leipnitz, Luciane; Arantes, Poliana C. C.; PereirA, Rogéria Costa (Orgs.). O ensino de alemão em contexto universitário. São Paulo, Humanitas, 2017.

UPhoff, Dörthe; LeIPNitz, Luciane; ArAntes, Poliana C. C.; PereIRA, Rogéria Costa (Orgs.). Alemão em contexto universitário. Ensino, pesquisa e extensão. São Paulo, FFLCH/USP, 2019.

WitTGensteIn, Ludwig. Über Gewissheit = On Certainty. Malden/Oxford: Blackwell, 2004. (= Da Certeza)

Recebido em 30 de abril de 2020 Aceito em 21 de julho de 2020 